\title{
Active and break spells of the Indian summer monsoon
}

\author{
M Rajeevan ${ }^{1, *}$, Sulochana Gadgil ${ }^{2}$ and Jyoti Bhate ${ }^{1}$ \\ ${ }^{1}$ National Atmospheric Research Laboratory, Gadanki 517 112, Andhra Pradesh, India. \\ ${ }^{2}$ Centre for Atmospheric and Oceanic Sciences, Indian Institute of Science, Bangalore 560 012, India. \\ *e-mail: rajeevan61@yahoo.co.in
}

In this paper, we suggest criteria for the identification of active and break events of the Indian summer monsoon on the basis of recently derived high resolution daily gridded rainfall dataset over India (1951-2007). Active and break events are defined as periods during the peak monsoon months of July and August, in which the normalized anomaly of the rainfall over a critical area, called the monsoon core zone exceeds 1 or is less than -1.0 respectively, provided the criterion is satisfied for at least three consecutive days. We elucidate the major features of these events. We consider very briefly the relationship of the intraseasonal fluctuations between these events and the interannual variation of the summer monsoon rainfall.

We find that breaks tend to have a longer life-span than active spells. While, almost $80 \%$ of the active spells lasted 3-4 days, only $40 \%$ of the break spells were of such short duration. A small fraction (9\%) of active spells and $32 \%$ of break spells lasted for a week or longer. While active events occurred almost every year, not a single break occurred in $26 \%$ of the years considered. On an average, there are 7 days of active and break events from July through August. There are no significant trends in either the days of active or break events. We have shown that there is a major difference between weak spells and long intense breaks. While weak spells are characterized by weak moist convective regimes, long intense break events have a heat trough type circulation which is similar to the circulation over the Indian subcontinent before the onset of the monsoon.

The space-time evolution of the rainfall composite patterns suggests that the revival from breaks occurs primarily from northward propagations of the convective cloud zone. There are important differences between the spatial patterns of the active/break spells and those characteristic of interannual variation, particularly those associated with the link to ENSO. Hence, the interannual variation of the Indian monsoon cannot be considered as primarily arising from the interannual variation of intraseasonal variation. However, the signature over the eastern equatorial Indian Ocean on intraseasonal time scales is similar to that on the interannual time scales.

\section{Introduction}

Indian summer monsoon, which is a part of the Asian monsoon system, exhibits a wide spectrum of variability, on daily, sub-seasonal, interannual, decadal and centennial time scales. During the summer monsoon season (June to September), a substantial component of this variability of convection and rainfall over the Indian region arises from the fluctuation on the intraseasonal scale between active spells with good rainfall and weak spells or breaks with little rainfall. The interannual variability of the sub-seasonal fluctuations during the monsoon season is large. Long intense breaks are known to have an impact on the seasonal monsoon rainfall over the country (Gadgil and Joseph 2003). Frequent or prolonged breaks during the monsoon season, such as the break in July 2002 (figure 1), can lead to drought conditions. Long breaks in critical growth periods of agricultural

Keywords. Indian monsoon; monsoon breaks; intraseasonal variability; monsoon circulation. 

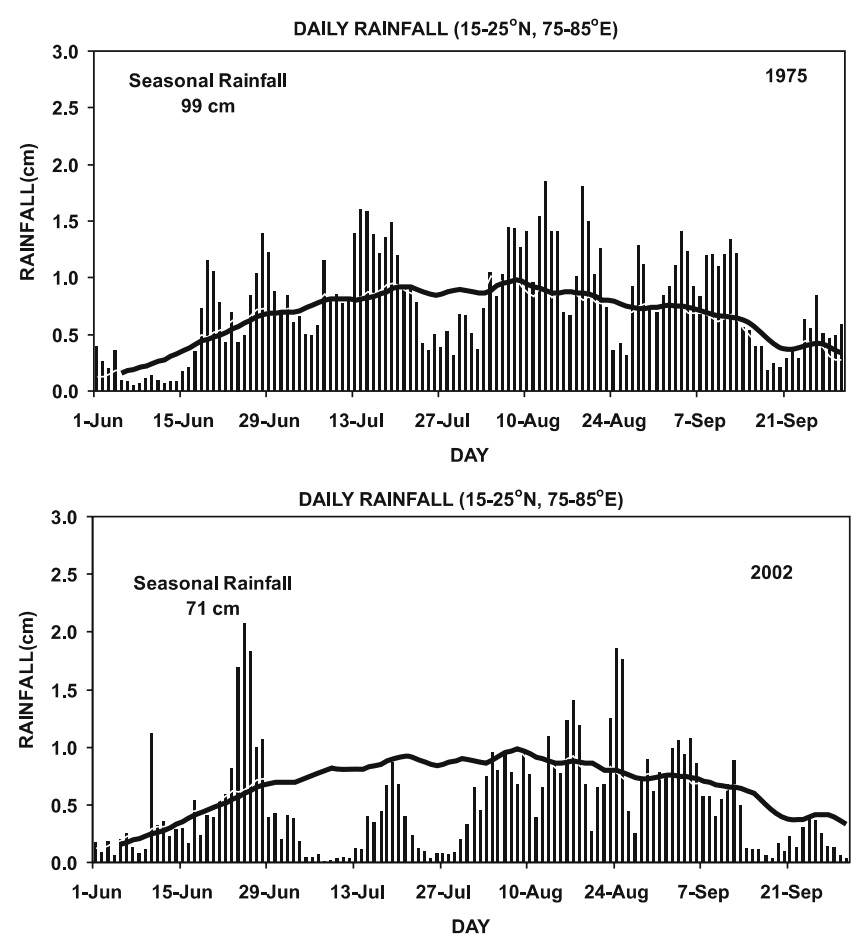

Figure 1. Variation of the daily rainfall over central India during June-September 1975 (excess monsoon year) and 2002 (drought year) shown as vertical bars. The long term mean is shown as a continuous line.

crops lead to substantially reduced yield (Gadgil et al 2003). Even in normal monsoon years, an uneven spatial and temporal distribution of rains has an adverse effect on agriculture. Therefore, prediction of intraseasonal variations and of the occurrence of breaks, and in particular, their duration and intensity, is very important.

Blanford (1886) first described this fluctuation in the rainfall over the monsoon trough zone between spells 'during the height of rains' and 'intervals of drought', and elucidated the nature of the pressure distribution and circulation associated with these phases of contrasting rainfall conditions. In his words, "The normal meeting place of the eastern and western branches of the monsoon is indicated by the trough of low pressure, which runs down from the Punjab to the southeast; the westerly branch prevailing to the southwest of this trough, and the easterly branch (more frequently in the Gangetic plain) to the northeast. This feature is seen in July mean pressure and surface wind pattern (figure 2). In intervals of drought, when northwesterly and westerly winds interrupt the monsoon in north-western and central India, it (the trough of low pressure) is pushed northward to the foot of the hills. On the other hand, during the height of rains at certain intervals, true cyclonic vortices, with closed isobars (barometric minima) are formed on or in the immediate neighbourhood of this trough". Blanford's

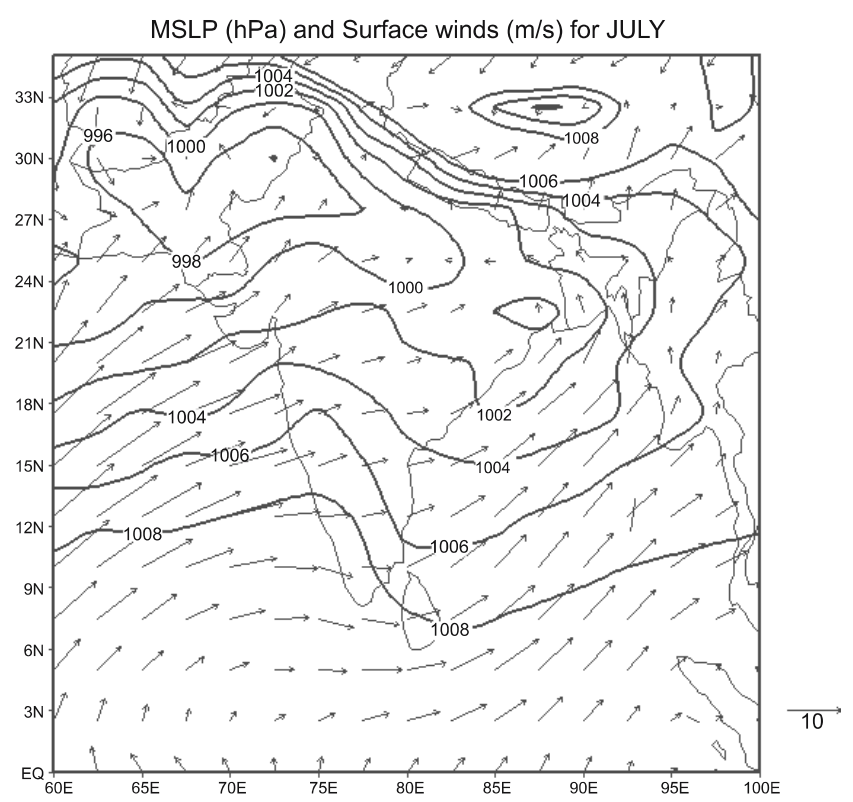

Figure 2. Mean sea level pressure $(\mathrm{hPa})$ and mean surface winds $\left(\mathrm{ms}^{-1}\right)$ for July derived from NCEP/NCAR reanalysis data (1968-2005).

(1886) 'intervals of droughts', during which the large-scale rainfall over the Indian monsoon zone is interrupted for several days in the peak monsoon months of July-August, have been called 'breaks' in the monsoon (e.g., Ramamurthy 1969; Raghavan 1973; Krishnamurti and Bhalme 1976; Alexander et al 1978; Sikka 1980, etc.). Although interruption of monsoon rainfall is recognized as the most important feature of the 'break', the criteria used by the India Meteorological Department (IMD) and by several meteorologists for identifying a 'break', are the low level pressure and wind patterns associated with such a rainfall anomaly, rather than the rainfall distribution itself (Rao 1976). In Ramamurthy's (1969) comprehensive study of breaks during 1888-1967, a break situation was defined as one in which the surface trough (the 'monsoon trough') is located close to the foothills, easterly winds disappear from the sea level and $850 \mathrm{hPa}$ charts (similar to the situation described by Blanford 1886), provided the condition persisted for at least two days. Subsequent to the classic work of Ramamurthy's (1969), De et al (1998) have identified the breaks during 1968-1997 using the same criteria.

Since the study of Ramamurthy (1969), active spells and weak spells/breaks of the Indian summer monsoon have been extensively studied, particularly in the last decade (e.g., Sikka and Gadgil 1980; Magana and Webster 1996; Rodwell 1997; Webster et al 1998; Krishnan et al 2000; Krishnamurthy and Shukla 2000, 2007, 2008; Annamalai and Slingo 2001; Goswami and Ajayamohan 2001; Lawrence and Webster 2001; 
De and Mukhopadhyay 2002; Gadgil and Joseph 2003; Goswami et al 2003; Waliser et al 2003; Kripalani et al 2004; Wang et al 2005; Mandke et al 2007 and the recent reviews by Goswami 2005 and Waliser 2006). However, different scientists have used the same term 'break', to denote different features of convection and/or circulation over different regions. Webster et al (1998) used the term 'break' as defined by Magana and Webster (1996) to denote weak spells of convection and $850 \mathrm{hPa}$ zonal winds over a larger region $\left(65-95^{\circ} \mathrm{E}, 10-20^{\circ} \mathrm{N}\right)$. On the other hand, Goswami and Ajayamohan (2001) defined 'breaks' on the basis of the strength of the $850 \mathrm{hPa}$ wind at the single grid-point $15^{\circ} \mathrm{N}$, $90^{\circ} \mathrm{E}$. Krishnan et al (2000) defined break days as days with positive OLR anomalies over northwest and central India (i.e., only over the western part of the monsoon trough zone), provided the average OLR anomaly over $73-82^{\circ} \mathrm{E}, 18-28^{\circ} \mathrm{N}$ exceeds $10 \mathrm{Wm}^{-2}$.

Since it is recognized that rainfall is the most important facet of the monsoon given its direct socio-economic impact, it has been the basis for the identification of active spells and breaks in many studies. However, even when the 'breaks' are identified in terms of rainfall or convection over the Indian region, a variety of definitions are used. Rodwell (1997) and Annamalai and Slingo (2001) used the term 'break' to denote weak spells of the daily all-India average rainfall calculated operationally by the IMD. Annamalai and Slingo (2001) used the daily all-India rainfall based on data at more than 200 stations representing the whole country. Mandke et al (2007) identified the active/break days on the basis of the precipitation anomaly over an area $73-82^{\circ} \mathrm{E}, 18-28^{\circ} \mathrm{N}$, which they called the Indian core region. The periods were identified as active (break) when the standardized rainfall anomaly over the Indian core region exceeds (less than) $0.7(-0.7)$ for three consecutive days during 15 June to 15 September. Krishnamurthy and Shukla (2000, 2007) used the all-India daily rainfall index (IMR) from the $1^{\circ}$ by $1^{\circ}$ rainfall data for 1901-1970, prepared from the IMD raingauge data (Hartmann and Michelson 1989) and Krishnamurthy and Shukla (2008) used the IMD gridded $1^{\circ}$ by $1^{\circ}$ rainfall data (Rajeevan et al 2006) for identifying the active and break spells. The threshold used for identifying the spells was one-half of the standard deviation of the IMR index. Gadgil and Joseph (2003) have defined breaks (and active spells) on the basis of the daily rainfall over the monsoon trough zone. They defined a break (active) day as a day on which the rainfall is below (above) the specified thresholds for western and eastern parts of the monsoon zone. The thresholds for defining a break were chosen so as to have maximum possible overlap with breaks identified by Ramamurthy (1969) and De et al (1998) on the basis of the synoptic situation as per the IMD definition (Rao 1976). The break composite of rainfall of Gadgil and Joseph (2003) is very similar to that of Ramamurthy (1969) with positive rainfall anomalies over the Himalayan foothills and southeastern peninsula.

Since different criteria are used for definitions of breaks in different studies, there are differences in the breaks identified, hence in their duration, their frequency of occurrence as well as the associated circulation and convection patterns. Clearly, it is important to decide on a reasonable and objective criterion for identifying breaks and active spells. In our view, the criteria should be based on rainfall as it is the critical facet of the monsoon (Krishnamurthy and Shukla 2002, 2007; Gadgil and Joseph 2003). In this paper, we suggest criteria for the identification of active and break spells on the basis of recently derived daily gridded rainfall dataset (Rajeevan et al 2006), which is routinely updated by the India Meteorological Department (IMD). The criteria were carefully chosen so that they can be used on real-time applications during the monsoon using operational daily rainfall analysis.

In section 2, details of the data used for this study are discussed. Section 3 deals with the criteria adopted for defining the active and break events, comparison with earlier studies and description of the important characteristics of these spells. In section 4 , the composites of active spells and breaks and their evolution are described. The relationship of the active spells and breaks, we have identified, with interannual variation of the Indian summer monsoon rainfall (ISMR) is briefly discussed in section 5. The important time scales in active spells and breaks and the transition between the two phases are considered in section 6 . The major features of intense long breaks in terms of the increase in surface temperature and the heat-trough type meridional circulation are elucidated in section 7 and the last section comprises a summary and concluding remarks.

\section{Data}

For the present study, we have used an updated version of the high resolution gridded daily rainfall data developed by Rajeevan et al (2006). The original dataset was developed for the period 1951-2003 using 1803 stations. The daily rainfall data were interpolated into grids of $1^{\circ} \times 1^{\circ}$ degree resolution using the Shepard (1968) interpolation method. Standard quality controls were made on the data before interpolating the data into regular grids. In the interpolation method, interpolated values 


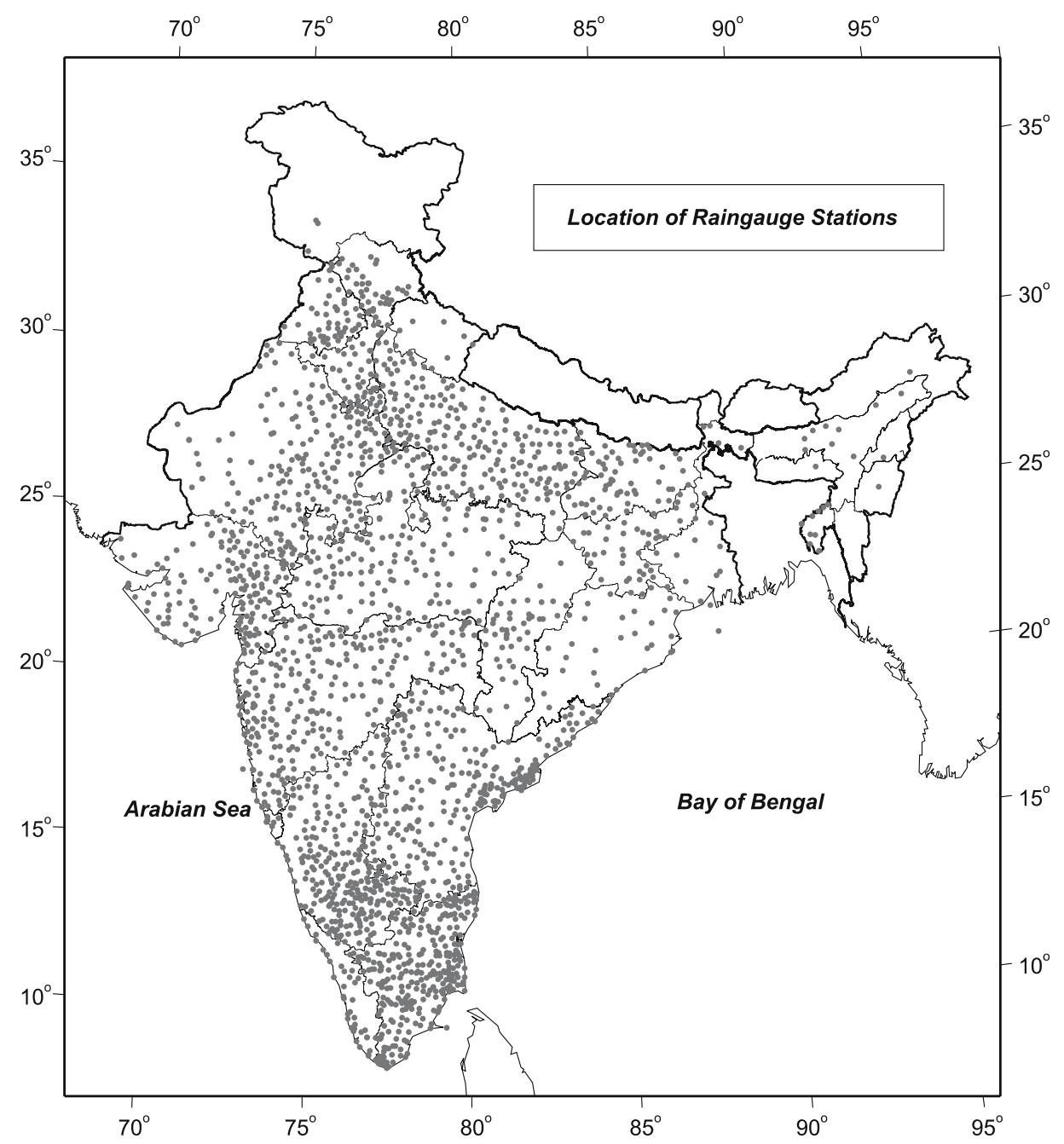

Figure 3. Network of raingauge stations considered for the development of high resolution gridded dataset.

are computed from a weighted sum of the observations. Given a grid point, the search distance is defined as the distance from this point to a given station. The interpolation is restricted to the radius of influence. We have also considered the method proposed by Shepard to locally modify the scheme for including the directional effects and barriers. In this method, no initial guess is required. More details of the development method are given in Rajeevan et al (2006).

In the original data analysis, there were many data gaps, especially over the northern parts of India. We have therefore updated this analysis by considering more stations (total 2140 stations instead of 1803 stations) from northern parts of India and thus improving the density of raingauge network. We have further extended the rainfall analysis to 2007 , thus making 57 years of daily rainfall data for the present study. IMD now compiles the daily data from more than 2000 stations on real time mode. Therefore, availability of daily station rainfall data is now assured on real time basis for the daily gridded rainfall analysis. The stations considered in this analysis were selected such that these stations have minimum $90 \%$ data availability during the analysis period. The network of stations considered for the analysis is shown in figure 3 . The basic rainfall data and the gridded rainfall products are available from the India Meteorological Department, Pune (www.imdpune.gov.in). More details of the density of network for each year and details of gridded analysis are given in Rajeevan et al (2006).

For examining the characteristics and circulation anomalies associated with the active/break events, we have used the daily re-analysis data of NCEP/NCAR (Kalnay et al 1996). The daily data of mean sea level pressure, wind data at $850 \mathrm{hPa}$ and $200 \mathrm{hPa}$ levels were used for the analysis. In addition, we have also used the daily OLR data measured from Advanced High Resolution Radiometers (AVHRR) aboard NOAA polar orbiting satellites. These data were obtained from Climate Diagnostics Centre, USA, http:// www.cdc.noaa.gov/. 


\section{Active and break events based on rainfall}

A large number of studies on monsoon breaks are based on the all-India average rainfall. However, the analysis by Krishnamurthy and Shukla (2000) showed that the dominant mode in the daily rainfall has anomalies of one sign over central India and anomalies of the opposite sign over the foothills of the Himalayas and over southeastern peninsula. Thus, the intraseasonal variations are not coherent over the entire Indian region and all-India average cannot be considered to be representative of the different subregions. The most conspicuous feature of the rainfall anomaly pattern of the monsoon breaks as obtained by Ramamurthy (1969) is the large negative rainfall anomaly over the plains of northwest and central India. Positive rainfall anomalies occur over northeast India, and also over southeastern peninsula. This rainfall pattern is similar to the dominant intraseasonal mode of Krishnamurthy and Shukla (2000).

Our identification of active spells and breaks is based on the updated version of the IMD gridded rainfall dataset, as discussed above. The criteria we adopt were derived from the rainfall over the region over which significant rainfall fluctuations between the active and break spells are observed, viz., the core monsoon zone (figure 4a). The core region is roughly from $18.0^{\circ} \mathrm{N}$ to $28.0^{\circ} \mathrm{N}$, and $65.0^{\circ} \mathrm{E}$ to $88.0^{\circ} \mathrm{E}$. The tropical convergence zone (TCZ) responsible for the large-scale rainfall during the summer monsoon gets established over the core monsoon zone at the culmination of the onset phase of the monsoon. During the peak monsoon months of July and August, the TCZ fluctuates primarily in this zone. By early September, the monsoon starts retreating from the western part of this zone. Traditionally dry spells are referred to as breaks only after the monsoon has been established over the core monsoon zone. We expect that some of the processes involved in the fluctuations in the intensity of rainfall in the seasonal transitions, i.e., onset and retreat phases of the monsoon to be different. Hence for identifying active and break spells, we have considered only July and August months. The spatial variation of the mean (19512006) rainfall during July-August is also shown in figure 4(a). While choosing this zone, care was taken not to include the foothills of Himalayas, where substantial amount of rainfall is received during the monsoon breaks. This core monsoon zone is very similar to the geographical area considered by Gadgil and Joseph (2003) for identifying active and break spells.

The average zonal rainfall is significantly correlated with the rainfall over different grids showing that the intraseasonal variation is coherent over

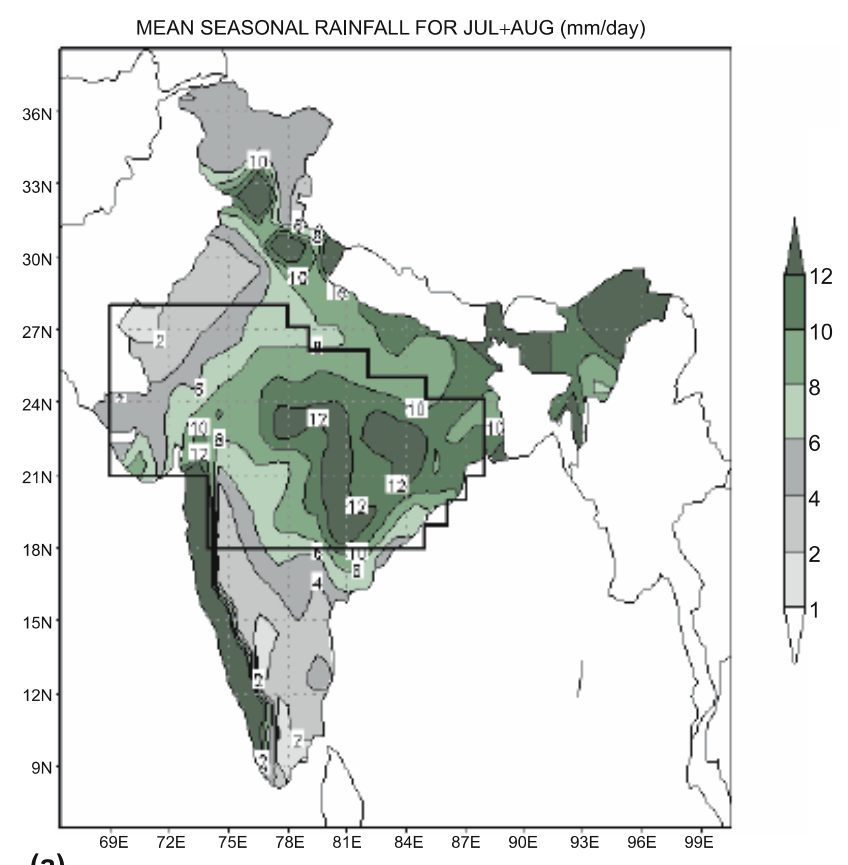

(a)

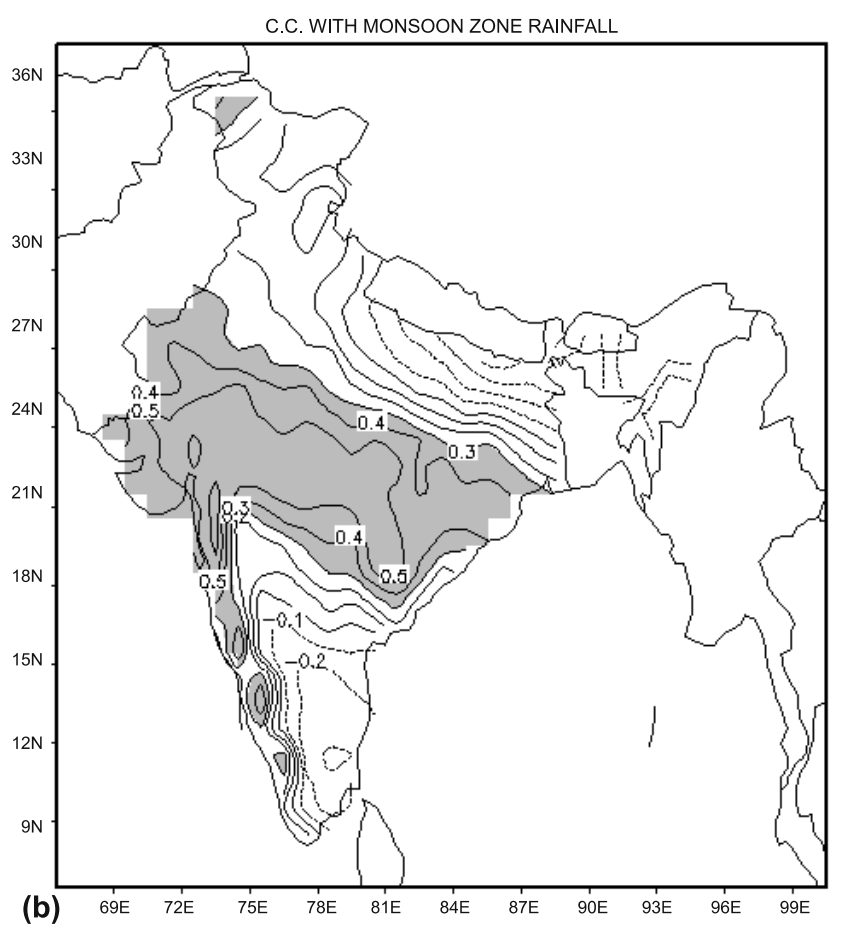

Figure 4. (a) Monsoon core zone considered to identify the active and break events. Mean (1951-2007) rainfall ( $\mathrm{mm} /$ day) during the period July and August is also shown. (b) Correlation coefficient of 5-day average rainfall over the monsoon zone with rainfall at all grid points. Rainfall during only July and August months have been considered.

this zone and the average rainfall over this zone is indeed representative of the rainfall within subregions of the zone (figure $4 \mathrm{~b}$ ). It is seen that the rainfall over northeast India and southeast peninsula is negatively correlated with the rainfall over the core monsoon zone. The correlation based only 


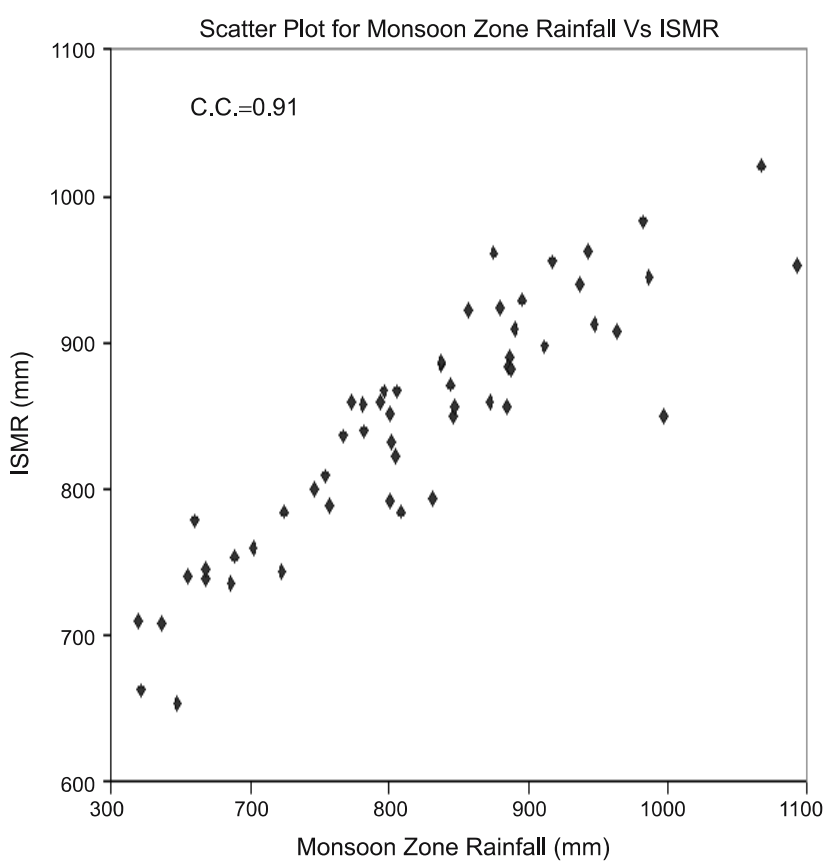

Figure 5. Scatter plot between the average rainfall over the monsoon core zone (June to September) and ISMR. Period: 1951-2007.

on the rainfall during the active and break spells is much higher throughout the core monsoon zone (not shown). The variation of the average all-India rainfall is seen to be very similar to the variation of the core monsoon zone rainfall and during August, the average all-India rainfall is almost the same as that of the core monsoon zone (not shown). The interannual variation of the all-India summer monsoon rainfall (ISMR) is highly correlated (correlation coefficient: 0.91 ) with that of the summer monsoon rainfall over the core monsoon zone (figure 5) suggesting that it is a critical region for the interannual variation.

Active and break events were identified by averaging the daily rainfall over this core monsoon zone and standardizing the daily rainfall time series by subtracting from its long term normal (1951-2000) and by dividing with its daily standard deviation. From figure 3, it can be seen that sufficient stations (803 stations) are available in this zone for averaging and preparing daily rainfall data. The break spell has been identified as the period during which the standardized rainfall anomaly is less than -1.0 , consecutively for three days or more. Similarly the active periods are identified as the periods during which the rainfall anomaly is more than +1.0 the standard deviation, consecutively for three days or more.

The break spells identified in this study using the above method (table 1) are comparable with those defined by Ramamurthy (1969) and De et al (1998) and there is a very large overlap with those identified by Gadgil and Joseph (2003). There are minor variations in the break spells identified by these methods. However, for the long breaks such as those in 1965, 1966, 1968, 1972, 1979 and 1982, there is a maximum overlap of break days among the three methods. It appears that the criterion based on the rainfall over the core monsoon zone for occurrences of breaks are somewhat more stringent than the one used by Ramamurthy (1969) and De et al (1998). Thus, during 1951-1989, no breaks occurred in three summer monsoon seasons as per the criterion of Ramamurthy (1969) and De et al (1998) whereas breaks did not occur in 10 monsoon seasons as per the present criteria and in eight monsoon seasons as per the Gadgil and Joseph's (2003) criterion. On the other hand, breaks identified according to the criteria adopted by Krishnan et al (2000) and Webster et al (1998) occur every year. These 'breaks' are thus weak spells of the active-weak fluctuations of the monsoon which occur every year. The new criteria can be applied very easily on operational basis to identify and monitor the active and break phases of monsoon. The operational monitoring product based on these new criteria is now made available by the India Meteorological Department (IMD) at http://www.imdpune.gov.in/mons_monitor/ mm_index.html.

The active spells identified by using the new criteria are shown in table 2. Active spells occur in almost every monsoon season. There were only two seasons without even a single active event. On the other hand, not a single break occurred in $26 \%$ of the years. On an average, during July and August, there are 7.2 and 7 days of active and break days respectively. The standard deviation of break spells (6.5 days) is much larger than the standard deviation of active spells (4.7 days). The average number of active days in July (3.8) is somewhat larger than in August (3.4); whereas the average number of break days in July (3.2) is smaller than that of August (3.8). The frequency distribution of the duration of breaks is similar to that of the breaks identified by Ramamurthy (1969) and Gadgil and Joseph (2003) (table 3). The frequency distribution of active spells is depicted in table 4 . We note that the mode is for short spells of 3-4 days for active events as well as breaks. However, breaks tend to have a longer life-span than active spells. While, almost $80 \%$ of the active spells lasted 3-4 days only $40 \%$ of the break spells were of such short duration. A small fraction (9\%) of active and 32\% of break spells lasted for a week or longer and, of these, almost $30 \%$ break spells persisted for more than 10 days.

It is important to note that active spells are characterized by a sequence of time-clustering partly overlapping development of monsoon disturbances 
Table 1. Monsoon break spells.

\begin{tabular}{|c|c|c|c|}
\hline Year & Present study & Gadgil and Joseph (2003) & $\begin{array}{l}\text { Ramamurthy (1969) up to } 1967, \\
\text { De et al (2002) from } 1968 \text { to } 1989\end{array}$ \\
\hline 1951 & $24-29 \mathrm{~A}$ & 14-15J, 24-30A & 1-3J, 11-13J, 15-17J, 24-29A \\
\hline 1952 & 9-13J.28-3QA & 1-3J, 10-13J, 27-30A & $9-12 \mathrm{~J}$ \\
\hline 1953 & - & - & $24-26 \mathrm{~J}$ \\
\hline 1954 & $22-28 \mathrm{~A}$ & $22-29 \mathrm{~A}$ & 18-29J, 21-25A \\
\hline 1955 & $24-26 J$ & $24-25 \mathrm{~J}$ & $22-29 \mathrm{~J}$ \\
\hline 1956 & - & $23-30 \mathrm{~A}$ & $23-26 \mathrm{~A}$ \\
\hline 1957 & - & $28-29 \mathrm{~J}$ & $27-31 \mathrm{~J}, 5-7 \mathrm{~A}$ \\
\hline 1958 & - & - & $10-14 \mathrm{~A}$ \\
\hline 1959 & & - & $16-18 \mathrm{~A}$ \\
\hline 1960 & $18-23 \mathrm{~J}$ & 20-24J, 30-31A & $16-21 \mathrm{~J}$ \\
\hline 1961 & - & - & - \\
\hline 1962 & $27-29 \mathrm{~J}$ & $27-28 \mathrm{~J}, 1-2 \mathrm{~A}, 7-8 \mathrm{~A}, 25-26 \mathrm{~A}$ & $18-22 \mathrm{~A}$ \\
\hline 1963 & 13-19J, 21-23J & 18-19J, 22-23J & 10-13J, 17-21J \\
\hline 1964 & $29 \mathrm{~J}-4 \mathrm{~A}$ & - & 14-18J, 28J-3A \\
\hline 1965 & $6-11 \mathrm{~J}, 1-14 \mathrm{~A}$ & $7-11 \mathrm{~J}, 4-14 \mathrm{~A}$ & $6-8 \mathrm{~J}, 4-15 \mathrm{~A}$ \\
\hline 1966 & $2-12 \mathrm{~J}, 21-31 \mathrm{~A}$ & $2-12 \mathrm{~J}, 22-31 \mathrm{~A}$ & $2-11 \mathrm{~J}, 23-27 \mathrm{~A}$ \\
\hline 1967 & $7-14 \mathrm{~J}$ & $6-15 \mathrm{~J}$ & $7-10 \mathrm{~J}$ \\
\hline 1968 & $25-31 \mathrm{~A}$ & $25-31 \mathrm{~A}$ & $25-29 \mathrm{~A}$ \\
\hline 1969 & - & $27-31 \mathrm{~A}$ & $17-20 \mathrm{~A}, 25-27 \mathrm{~A}$ \\
\hline 1970 & 13-19J & 14-19J, 23-26J & $12-25 \mathrm{~J}$ \\
\hline 1971 & $8-10 \mathrm{~J}, 5-7 \mathrm{~A}, 17-20 \mathrm{~A}$ & $8-10 \mathrm{~J}, 5-6 \mathrm{~A}, 18-19 \mathrm{~A}$ & $17-20 \mathrm{~A}$ \\
\hline 1972 & $18 \mathrm{~J}-3 \mathrm{~A}$ & $19 \mathrm{~J}-3 \mathrm{~A}$ & $17 \mathrm{~J}-3 \mathrm{~A}$ \\
\hline 1973 & $24-26 \mathrm{~J}, 31 \mathrm{~J}-2 \mathrm{~A}$ & 24-26J, 30J-1A & $23 \mathrm{~J}-1 \mathrm{~A}$ \\
\hline 1974 & $29-31 \mathrm{~A}$ & $24-26 \mathrm{~A}, 29-31 \mathrm{~A}$ & $30-31 \mathrm{~A}$ \\
\hline 1975 & - & - & $24-28 \mathrm{~J}$ \\
\hline 1976 & - & $3-4 \mathrm{~J}, 21-22 \mathrm{~A}$ & - \\
\hline 1977 & $15-20 \mathrm{~A}$ & $15-19 \mathrm{~A}$ & $15-18 \mathrm{~A}$ \\
\hline 1978 & - & - & $16-21 \mathrm{~J}$ \\
\hline 1979 & $2-6 \mathrm{~J}, 14-29 \mathrm{~A}$ & $2-6 \mathrm{~J}, 15-31 \mathrm{~A}$ & $17-23 \mathrm{~J}, 15-31 \mathrm{~A}$ \\
\hline 1980 & $17-20 \mathrm{~J}, 13-15 \mathrm{~A}$ & $17-20 \mathrm{~J}, 14-15 \mathrm{~A}$ & $17-20 \mathrm{~J}$ \\
\hline 1981 & $24-27 \mathrm{~A}$ & $19-20 \mathrm{~A}, 24-31 \mathrm{~A}$ & 26-30J, 23-27A \\
\hline 1982 & $1-8 \mathrm{~J}$ & $1-8 \mathrm{~J}$ & - \\
\hline 1983 & $23-25 \mathrm{~A}$ & $8-9 \mathrm{~J}, 24-26 \mathrm{~A}$ & $22-25 \mathrm{~A}$ \\
\hline 1984 & $27-29 \mathrm{~J}$ & - & $20-24 \mathrm{~J}$ \\
\hline 1985 & $23-25 \mathrm{~A}$ & $2-3 \mathrm{~J}, 23-25 \mathrm{~A}$ & $22-25 \mathrm{~A}$ \\
\hline 1986 & $22-31 \mathrm{~A}$ & $1-4 \mathrm{~J}, 31 \mathrm{~J}-2 \mathrm{~A}, 22-31 \mathrm{~A}$ & $23-26 \mathrm{~A}, 29-31 \mathrm{~A}$ \\
\hline 1987 & $23-25 \mathrm{~J}, 30 \mathrm{~J}-4 \mathrm{~A}, 8-13 \mathrm{~A}, 16-18 \mathrm{~A}$ & $16-17 \mathrm{~J}, 23-24 \mathrm{~J}, 31 \mathrm{~J}-4 \mathrm{~A}, 11-13 \mathrm{~A}$ & $28 \mathrm{~J}-1 \mathrm{~A}$ \\
\hline 1988 & $14-17 \mathrm{~A}$ & $14-17 \mathrm{~A}$ & $5-8 \mathrm{~J}, 13-15 \mathrm{~A}$ \\
\hline 1989 & $18-20 \mathrm{~J}, 30 \mathrm{~J}-3 \mathrm{~A}$ & $30-31 \mathrm{~J}$ & 10-12J, 29-31J \\
\hline 1990 & - & & \\
\hline 1991 & - & & \\
\hline 1992 & $4-11 \mathrm{~J}$ & & \\
\hline 1993 & $20-23 \mathrm{~J}, 7-13 \mathrm{~A}, 22-28 \mathrm{~A}$ & & \\
\hline 1994 & - & & \\
\hline 1995 & $3-7 \mathrm{~J}, 11-16 \mathrm{~A}$ & & \\
\hline 1996 & $10-12 \mathrm{~A}$ & & \\
\hline 1997 & $11-15 \mathrm{~J}, 9-14 \mathrm{~A}$ & & \\
\hline 1998 & $20-26 \mathrm{~J}, 16-21 \mathrm{~A}$ & & \\
\hline 1999 & $1-5 \mathrm{~J}, 12-16 \mathrm{~A}, 22-25 \mathrm{~A}$ & & \\
\hline 2000 & $1-9 \mathrm{~A}$ & & \\
\hline 2001 & $31 \mathrm{~J}-2 \mathrm{~A}, 26-30 \mathrm{~A}$ & & \\
\hline 2002 & $4-17 \mathrm{~J}, 21-31 \mathrm{~J}$ & & \\
\hline 2003 & - & & \\
\hline 2004 & 10-13J, 19-21J, 26-31A & & \\
\hline 2005 & $7-14 \mathrm{~A}, 24-31 \mathrm{~A}$ & & \\
\hline 2006 & - & & \\
\hline 2007 & $18-22 \mathrm{~J}, 15-17 \mathrm{~A}$ & & \\
\hline
\end{tabular}


Table 2. Monsoon active spells.

\begin{tabular}{|c|c|}
\hline Year & Active spells \\
\hline 1951 & $25-27 \mathrm{~J}$ \\
\hline 1952 & $23-31 \mathrm{~J}$ \\
\hline 1953 & $3-5 \mathrm{~A}, 12-19 \mathrm{~A}$ \\
\hline 1954 & $9-12 \mathrm{~A}$ \\
\hline 1955 & $29-31 \mathrm{~A}$ \\
\hline 1956 & $2-8 \mathrm{~J}, 11-14 \mathrm{~J}, 1-5 \mathrm{~A}$ \\
\hline 1957 & $20-23 \mathrm{~A}$ \\
\hline 1958 & $8-11 \mathrm{~J}$ \\
\hline 1959 & $12-14 \mathrm{~J}, 26-29 \mathrm{~J}$ \\
\hline 1960 & $1-4 \mathrm{~J}, 15-17 \mathrm{~A}$ \\
\hline 1961 & 6-10J, 16-18J, 24-26A \\
\hline 1962 & $16-18 \mathrm{~J}, 12-14 \mathrm{~A}$ \\
\hline 1963 & $10-12 \mathrm{~A}$ \\
\hline 1964 & $5-7 \mathrm{~J}, 15-17 \mathrm{~A}, 23-25 \mathrm{~A}$ \\
\hline 1965 & $26-29 \mathrm{~J}, 24-26 \mathrm{~A}$ \\
\hline 1966 & - \\
\hline 1967 & $1-3 \mathrm{~J}, 24-29 \mathrm{~J}$ \\
\hline 1968 & 5-10J, 29-31J, 4-6A \\
\hline 1969 & $29 \mathrm{~J}-1 \mathrm{~A}$ \\
\hline 1970 & 1-3J, 17-20A, 27-29A \\
\hline 1971 & $19-21 \mathrm{~J}, 26-31 \mathrm{~A}$ \\
\hline 1972 & $5-7 \mathrm{~J}$ \\
\hline 1973 & 7-9J, 13-15J, 12-14A, 18-20A, 26-31A \\
\hline 1974 & $17-20 \mathrm{~A}$ \\
\hline 1975 & $13-16 \mathrm{~J}, 12-15 \mathrm{~A}$ \\
\hline 1976 & $16-18 \mathrm{~J}, 28-31 \mathrm{~A}$ \\
\hline 1977 & $5-7 \mathrm{~J}$ \\
\hline 1978 & 7-10J, 15-17A, 24-30A \\
\hline 1979 & $3-5 \mathrm{~A}, 7-12 \mathrm{~A}$ \\
\hline 1980 & $1-3 \mathrm{~J}$ \\
\hline 1981 & $7-10 \mathrm{~J}$ \\
\hline 1982 & $12-14 \mathrm{~A}, 17-23 \mathrm{~A}$ \\
\hline 1983 & $18-21 \mathrm{~J}, 18-20 \mathrm{~A}$ \\
\hline 1984 & 3-6A, 9-11A, 15-19A \\
\hline 1985 & 15-17J, 30J-3A, 6-9A \\
\hline 1986 & $21-24 \mathrm{~J}, 13-15 \mathrm{~A}$ \\
\hline 1987 & $24-29 \mathrm{~A}$ \\
\hline 1988 & $26-28 \mathrm{~J}$ \\
\hline 1989 & - \\
\hline 1990 & $21-24 \mathrm{~A}, 29-31 \mathrm{~A}$ \\
\hline 1991 & $29-31 J$ \\
\hline 1992 & 26-29J, 16-18A \\
\hline 1993 & $7-9 \mathrm{~J}, 15-18 \mathrm{~J}$ \\
\hline 1994 & $2-4 \mathrm{~J}, 9-17 \mathrm{~J}, 18-20 \mathrm{~A}, 25-27 \mathrm{~A}$ \\
\hline 1995 & $18-25 \mathrm{~J}$ \\
\hline 1996 & 24-28J, 19-22A \\
\hline 1997 & $30 \mathrm{~J}-1 \mathrm{~A}, 20-26 \mathrm{~A}$ \\
\hline 1998 & $3-6 \mathrm{~J}$ \\
\hline 1999 & - \\
\hline 2000 & $12-15 \mathrm{~J}, 17-20 \mathrm{~J}$ \\
\hline 2001 & $9-12 \mathrm{~J}$ \\
\hline 2002 & - \\
\hline 2003 & $26-28 \mathrm{~J}$ \\
\hline 2004 & $30 \mathrm{~J}-1 \mathrm{~A}$ \\
\hline 2005 & $1-4 \mathrm{~J}, 27 \mathrm{~J}-1 \mathrm{~A}$ \\
\hline 2006 & 3-6J, 28J-2A, 5-7A, 13-22A \\
\hline 2007 & $1-4 \mathrm{~J}, 6-9 \mathrm{~J}, 6-9 \mathrm{~A}$ \\
\hline
\end{tabular}

Table 3. Frequency distribution of the duration of break spells in per cent.

\begin{tabular}{lccc}
\hline & \multicolumn{3}{c}{ Monsoon breaks } \\
\cline { 2 - 4 } Duration & $\begin{array}{c}\text { Present } \\
\text { study }\end{array}$ & $\begin{array}{c}\text { Gadgil and } \\
\text { Joseph }\end{array}$ & Ramamurthy \\
\hline $3-4$ & 40 & 44.8 & 49.5 \\
$5-6$ & 28 & 22.8 & 19.8 \\
$7-8$ & 19 & 14.3 & 16.2 \\
$9-10$ & 3 & 6.7 & 6.3 \\
$11-12$ & 4 & 4.8 & 4.5 \\
$13-14$ & 3 & 3.8 & 1 \\
$>15$ & 3 & 2.8 & 2.7 \\
\hline
\end{tabular}

Table 4. Frequency distribution of the duration of active spells in per cent.

\begin{tabular}{lc}
\hline Duration & Present study \\
\hline $3-4$ & 79 \\
$5-6$ & 12 \\
$7-8$ & 6 \\
$9-10$ & 3 \\
$>10$ & 0 \\
\hline
\end{tabular}

(Murakami 1976) and cyclonic vorticity above the boundary layer (Sikka and Gadgil 1978). The active phase is associated with lows and depressions, which form over Bay of Bengal and move across the monsoon core zone. The average lifespan of these synoptic systems is about 3-4 days. Therefore, active spells with the stringent criterion of the standardized rainfall anomaly of the core monsoon zone $>1.0$, generally last for $3-4$ days. Genesis and propagation of the synoptic scale systems in quick succession leads to longer active spells of about a week. Thus, the active phase is governed by synoptic scale disturbances which are a manifestation of fast growing convective instability. During the weak spells, strength of the cyclonic vorticity and the rainfall over the monsoon zone is much less than that for active spells. On the other hand, the break phase is characterized by a marked change in the lower tropospheric circulation over the monsoon zone, with the vorticity above the boundary layer becoming anticyclonic (Ramamurthy 1969; Sikka and Gadgil 1978). The break is, therefore, a special case of a weak spell with well defined circulation characteristics (Ramamurthy 1969). This is a stable state of the atmosphere over the monsoon zone which persists until a synoptic scale system or a northward propagating TCZ comes over the monsoon zone. Hence it is not surprising that there are more break spells with long life-span compared to active spells, as observed in this study. It is interesting that Goswami et al (2003) and Pai et al (2009) found a similar tendency of quicker transition from 

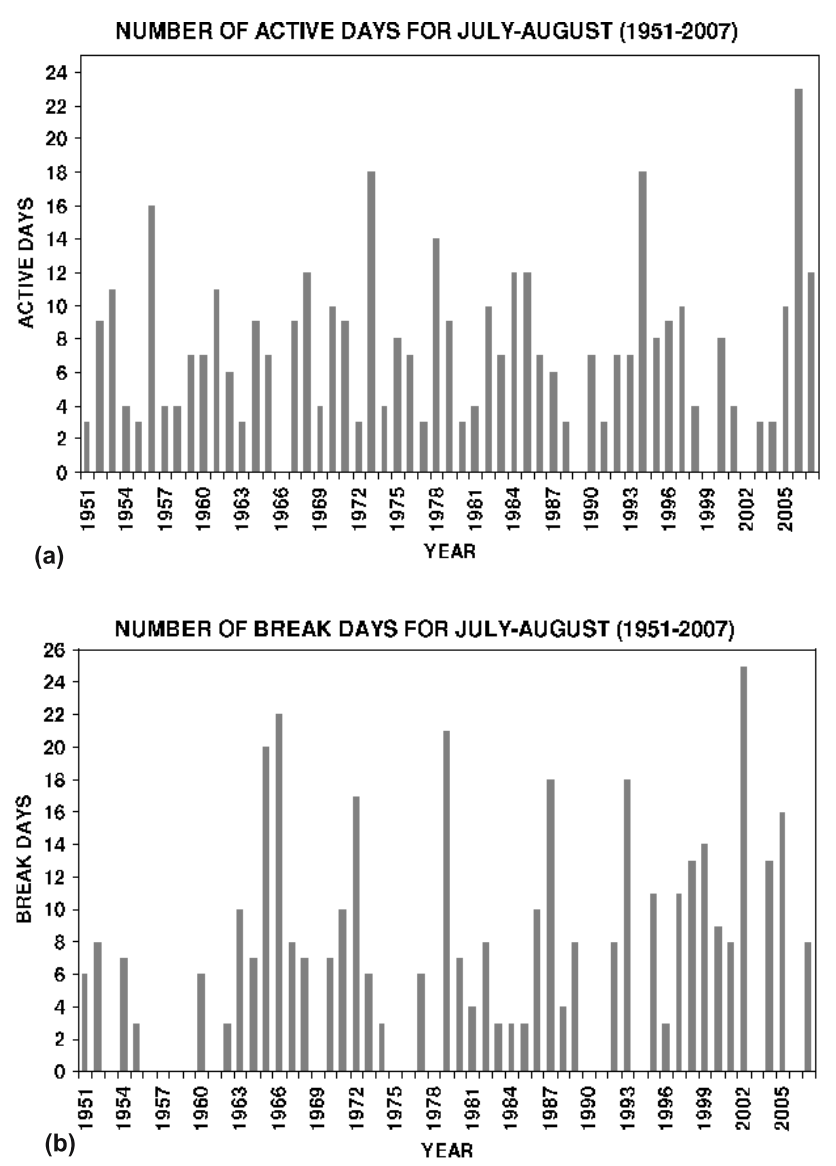

Figure 6. Time series of (a) active days and (b) break days during July and August. Period: 1951-2007.

active phase to break phase compared to break to active phase.

The variation of the number of active and break days during the summer monsoon for the period 1951-2007 is shown in figure 6(a) and (b), respectively. During the period 1951-2007, the maximum number of break days occurred in 2002 (25 days in July) while the maximum number of active days (22 days) occurred in 2006. The longest break spell (16 days) occurred in 1979 from 14-29 August. During 2002, two separate break spells occurred, from 4-17 July and then from 21-31 July. Joseph and Simon (2005) have reported that the number of break days (defined as those with mean zonal wind at $850 \mathrm{hPa}$ from the $\mathrm{NCEP} / \mathrm{NCAR}$ reanalysis in the box $10-20^{\circ} \mathrm{N}, 70-80^{\circ} \mathrm{E}$, equal to or less than $9 / 11 \mathrm{~m} \mathrm{~s}^{-1}$ during June-September), increased by 20-30\% during the period 1950-2002. However, we find no statistically significant trends during 1951-2007, either in the number of break or active days during the monsoon season (June to September) each year identified by using the rainfall criterion for active and break spells used in this study. It is possible that the trend they observed in the number of break days based on wind could have arisen from combining the data from pre-satellite era to the recents period.

\section{Rainfall composites and evolution of active and weak spells}

In this section, we discuss the evolution of composite active and break phases of monsoon. The evolution of the active and break phases is elucidated with lagged composites of daily rainfall anomalies for lags ranging from -12 to +12 days (figure $7 \mathrm{a}$ and $\mathrm{b}$ ). Lag-0 refers to the midpoint of the break/active period. Evolution of the active spells has some interesting features. Twelve days before the active spell (at lag -12), a large part of the monsoon zone has negative rainfall anomalies whereas there is a belt just to the south of about $20^{\circ} \mathrm{N}$ with positive anomalies and the west coast also has positive anomalies of rainfall. In the next ten days, this zonal band of positive anomalies shifts northwards, intensifies and expands and at lag- 0 , the pattern is the mirror image of the break spell with negative anomalies over the foothills and positive anomalies over the monsoon zone as well as the west coast. By lag +4 days, the region of positive anomalies shrinks and moves northward and by lag +8 , negative anomalies occur over most of the peninsular region, including the west coast.

Eight days before the break (at lag -8 days), negative rainfall anomalies appear over the western part of the monsoon zone and the west coast, which increase and slowly expand northwestwards. At lag -4, the negative rainfall anomalies cover the entire monsoon zone whereas positive anomalies are seen along the foothills of the Himalayas (associated with the shift in the monsoon trough over that region) and over southeastern peninsula. The same pattern (albeit with more intense negative anomalies) characterizes the break (lag-0). From lag +2 days, positive anomalies over the peninsula spread northward and westward and subsequently cover the monsoon zone and the west coast by lag +12 . At lag +12 , negative anomalies are restricted to the foothills of the Himalayas and large positive anomalies are observed along the west coast. Thus, from the evolution of the composite patterns, it appears that the revival from breaks seems to occur primarily from northward propagations. This feature is also seen in the evolution of breaks and active spells of Krishnamurthy and Shukla (2008).

The rainfall anomaly composite over the Indian region for breaks discussed in this study is similar to that of Ramamurthy (1969). While the present study used higher resolution $\left(1^{\circ} \times 1^{\circ}\right)$ data, Ramamurthy (1969) used rainfall data of meteorological subdivisions. The composite of rainfall for active spells is almost a mirror image of the break composite. During breaks and active spells, the rainfall anomaly is seen to be homogenous over the core monsoon zone and also along the west coast. However, the anomalies over northeast India and southeast peninsula are of the opposite sign. 
Lagged Composites of Daily Rainfall Anomalies for Break Period
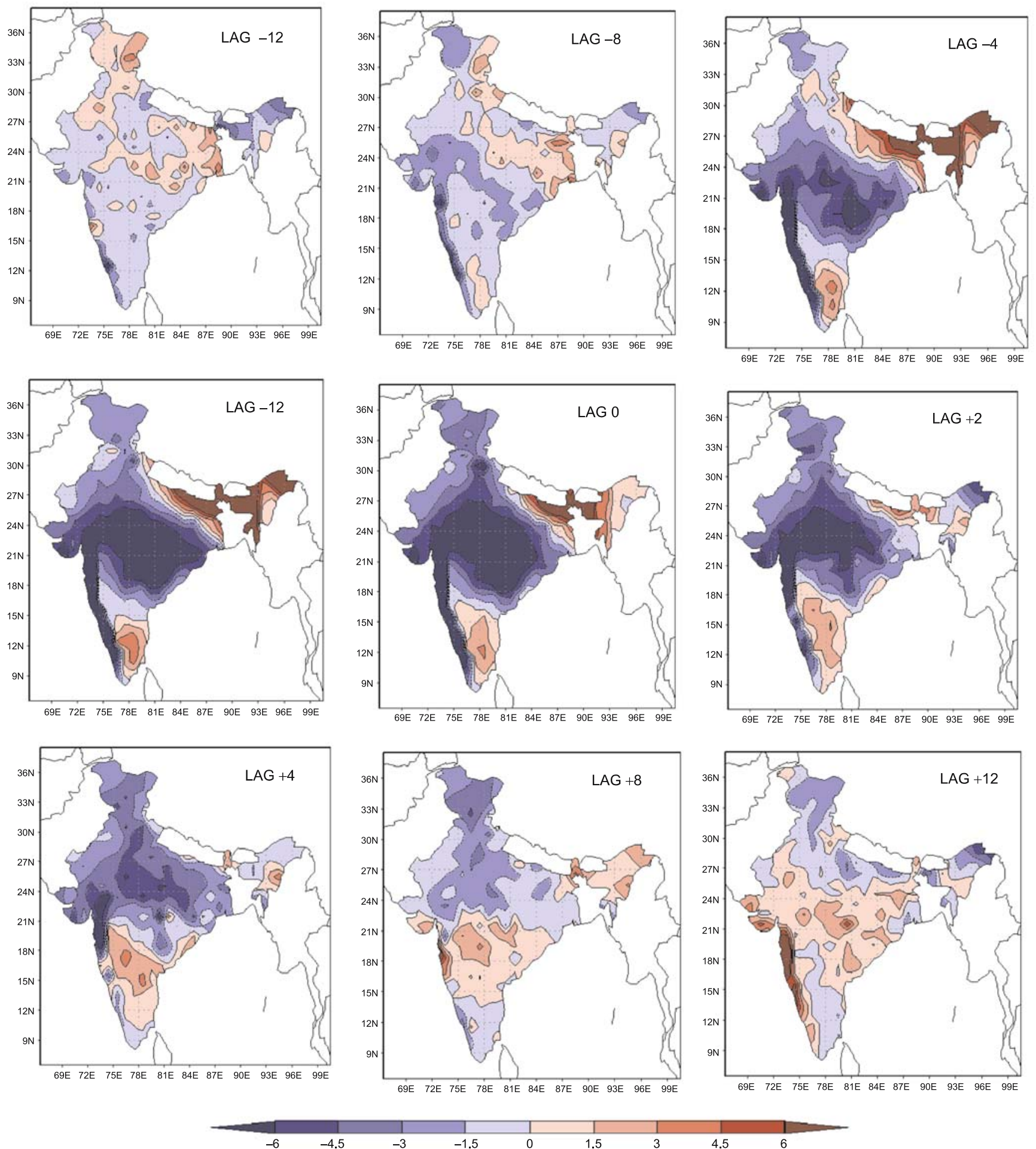

Figure 7(a). Lagged rainfall (mm) composites during the break spells (1951-2004).

\section{Intraseasonal and interannual variations of ISMR}

The relationship of the interannual variation of the monsoon with intraseasonal variation between active spells and breaks has been extensively studied. It has been shown that the major difference between the rainfall variation in good and some poor monsoon seasons is the occurrence of a long dry spell (break) in the latter (e.g., comparison of the daily rainfall over central India during the excess monsoon season of 1975 and the 

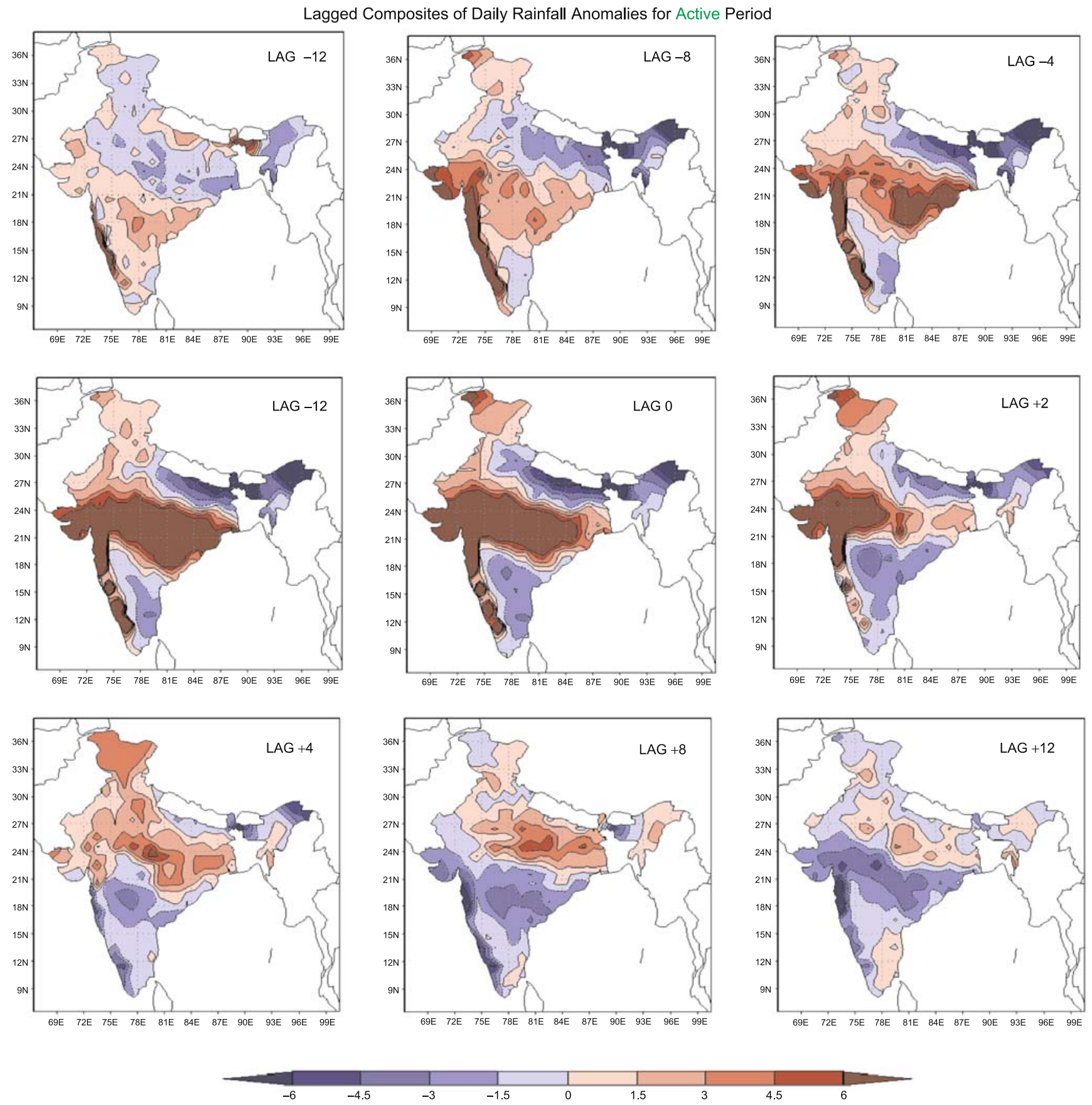

Figure 7(b). Lagged rainfall (mm) composites for the active spells (1951-2004).

drought of 2002 in figure 1). While it is recognized that intraseasonal variation and particularly, long intense breaks can have an impact on the seasonal total rainfall of the Indian monsoon, there is no consensus as yet on the extent of the contribution of the intraseasonal variation to the interannual variation. Ferranti et al (1997), Goswami et al (1998) and Goswami (2005) suggest that the intraseasonal and interannual variability are governed by a common spatial mode of variability. According to Goswami and Ajayamohan (2001), a higher probability of active (break) conditions within a season is associated with a stronger (weaker) than normal monsoon. On the other hand, Krishnamurthy and Shukla (2000) showed that the nature of intraseasonal variability is not different during the years of major droughts or major floods. The multi-channel singular spectrum analysis of Krishnamurthy and Shukla (2008) using OLR data reveals two dominant intraseasonal oscillatory modes and two large-scale standing patterns, one over the equatorial Pacific and the 

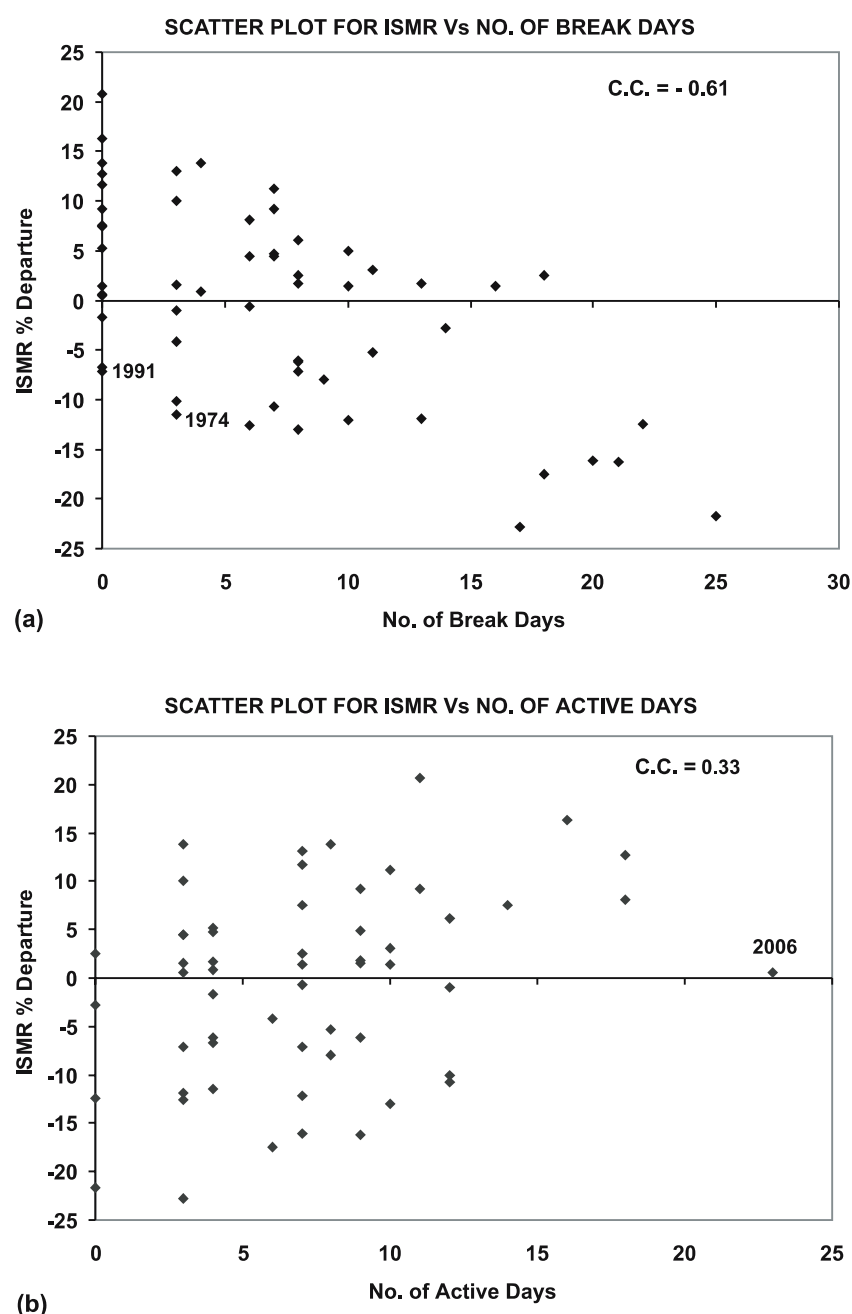

Figure 8. Scatter plot between (a) number of break days and ISMR and (b) number of active days and ISMR. Period: 1951-2007.

other over the equatorial Indian Ocean. They show that seasonal rainfall is determined mainly by two persisting large-scale standing patterns, without much contribution from the oscillatory modes.

The variation of the ISMR with the number of break days and active days in July-August of that year is shown in figure 8( $\mathrm{a}$ and $\mathrm{b})$, respectively. It is seen that ISMR is significantly negatively correlated with the number of break days. The magnitude of the correlation between ISMR and number of break days is high (0.61) and statistically significant. However, there is also large scatter. Note that even in the absence of breaks, the rainfall was deficit by almost 10\% in one year (1991) and with only 3 break days, the season of 1974 was a drought. The correlation with the number of active days is relatively poor. Thus, it is not surprising that the ISMR was near the average value for monsoon season with the largest number of active days, viz., 2006. The low correlation with the number of active days is consistent with the result that the all-India rainfall is not well correlated with the number of depressions or depression days but is largely determined by the lower intensity systems (Sikka 1980; Mooley and Shukla 1987). However, it can be noted that probability of above (below) normal ISMR is very high when the active (break) days during the July and August is more than 10 days.

The active and break composites of the OLR anomaly patterns are shown in figure 9 . The break composite is characterized by large positive OLR anomalies over the core monsoon zone and the equatorial west Pacific and central Pacific and large negative OLR anomalies over the eastern equatorial Indian Ocean and northern west Pacific $\left(120-130^{\circ} \mathrm{E}, 20-30^{\circ} \mathrm{N}\right)$. Thus, over $70-130^{\circ} \mathrm{E}$, the quadrapole pattern described by Annamalai and Slingo (2001) is seen. The active composite has large negative OLR anomalies over the core monsoon zone and over the equatorial central and west Pacific. Positive anomalies are seen over the eastern equatorial Indian Ocean. Over the equatorial east Indian Ocean, largest anomaly difference in OLR anomalies between the active and break events was noted. This is a critical area, which is physically linked to the active and break cycle of the Indian monsoon as discussed in the next section.

The relationship of the interannual variation of ISMR with the convection over the Indian and Pacific Oceans is shown in figure 10(a). It is seen that ISMR is negatively correlated with the convection over the central Pacific, which is a manifestation of the well known ENSO-monsoon relationship on the interannual scale (Sikka 1980; Rasmusson and Carpenter 1983 and several subsequent studies). This is clear from the correlation of OLR with ENSO index (which is defined as the negative of the normalized Nino 3.4 SST anomaly, so that it is positive when ENSO index is favourable for the monsoon) depicted in figure 10(b). It is seen that the impact of ENSO is suppression/enhancement over the equatorial and north Indian Ocean as well as the Indian region.

ISMR is positively correlated with convection over the western equatorial Indian Ocean and negatively correlated with convection over the eastern equatorial Indian Ocean. The equatorial Indian Ocean Oscillation (EQUINOO, Gadgil et al 2004) is characterized with convection anomalies of opposite signs over the western and equatorial Indian Ocean. The correlation of OLR with the index of EQUINOO (Gadgil et al 2004), which is again defined so that it is positive when favourable for the monsoon, is shown in figure 10(c). It is seen that the large positive correlation of ISMR with convection over the western equatorial Indian Ocean 

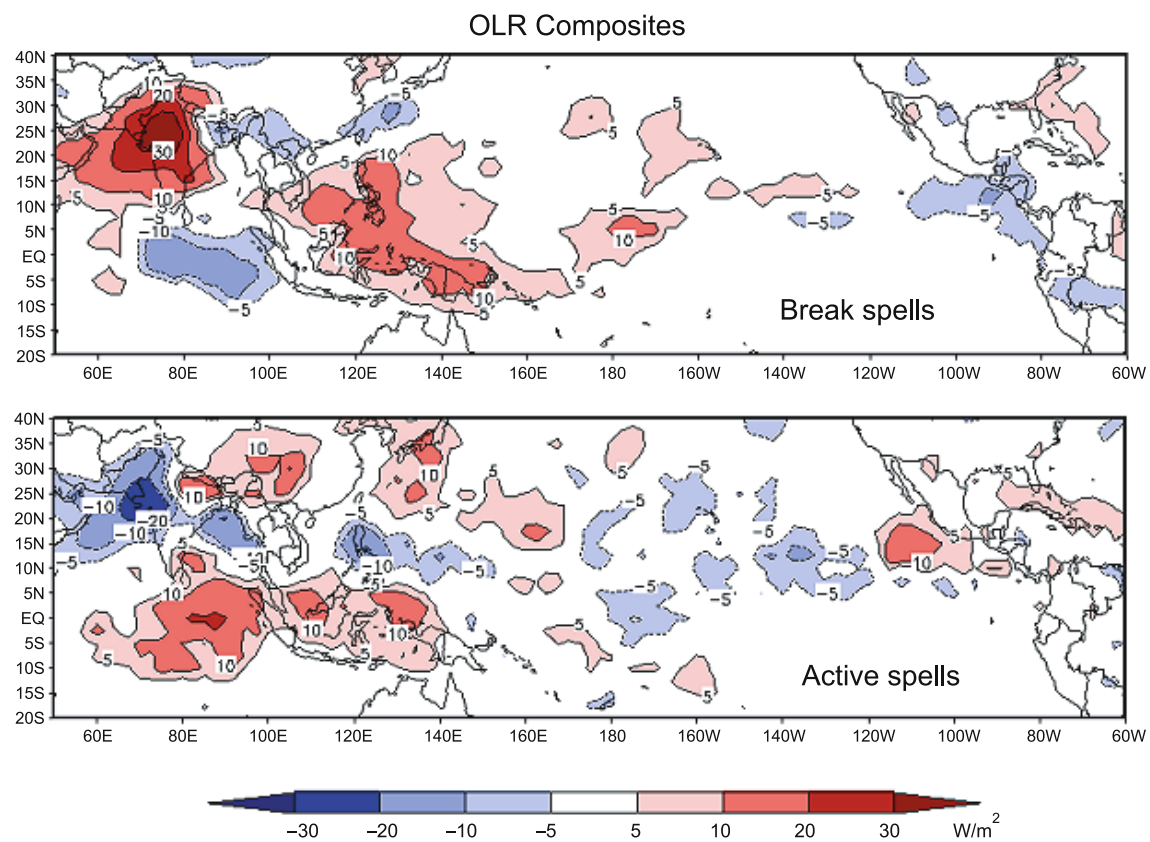

Figure 9. Composites of OLR anomalies $\left(\mathrm{Wm}^{-2}\right)$ during (a) break and (b) active spells. Period of analysis: $1979-2007$.

is a manifestation of the link of the interannual variation of ISMR with EQUINOO (Gadgil et al 2004, 2007). The two standing persistent modes over the Indian-west Pacific region identified by Krishnamurthy and Shukla (2008) are the ENSO and EQUINOO modes. Gadgil et al (2003, 2004) showed that there is a strong relationship between the extremes (droughts and excess monsoon seasons) and a composite index which is a linear combination of the ENSO index and EQWIN. Using a longer dataset (from 1881 to 1998), Ihara et al (2007) showed that the variation of ISMR is better described by the use of indices of ENSO as well as EQWIN than by ENSO index alone. The inference of Krishnamurthy and Shukla (2008) on the importance of these two modes for interannual variation of the monsoon is consistent with these studies demonstrating the importance of ENSO and EQUINOO.

Comparison of figures $9(\mathrm{a}$ and $\mathrm{b})$ with $10(\mathrm{a}$ and $\mathrm{b})$ shows that the pattern of convection anomalies over the central Pacific associated with breaks and active spells is opposite to that characteristic of the interannual variation of ISMR associated with the ENSO. On the other hand, figures $9(a$ and $b$ ) and 10(a and $c)$ show that the intraseasonal anomaly patterns over the eastern equatorial Indian Ocean are similar to those on the interannual scale associated with the link to EQUINOO. Thus, there are important differences between the spatial patterns of the active/break spells and those characteristic of interannual variation, particularly those associated with the link
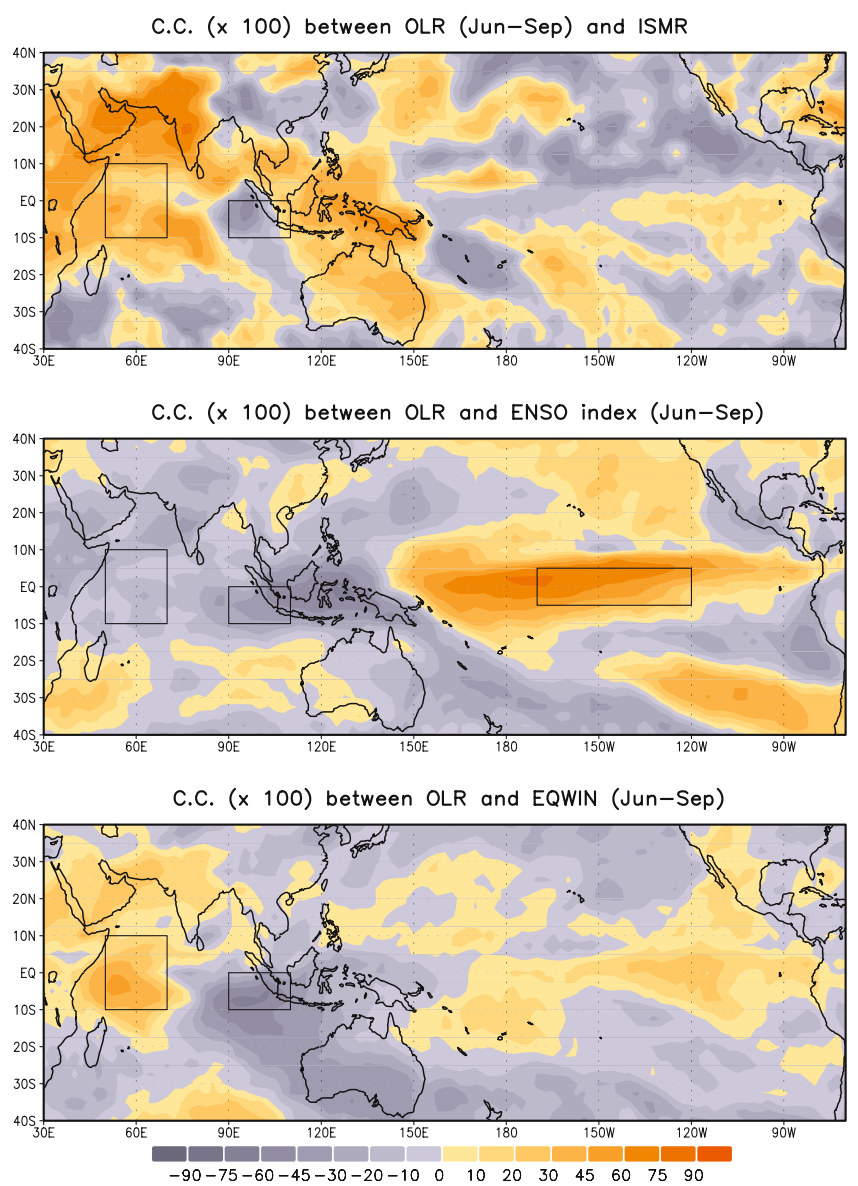

Figure 10. (a) Correlation $(\times 100)$ between OLR and ISMR during June to September, (b) ENSO index is the negative of the normalized SST anomaly of Nino 3.4 so that positive values are favourable for the monsoon, and (c) correlation $(\times 100)$ between OLR and EQWIN during June to September. 


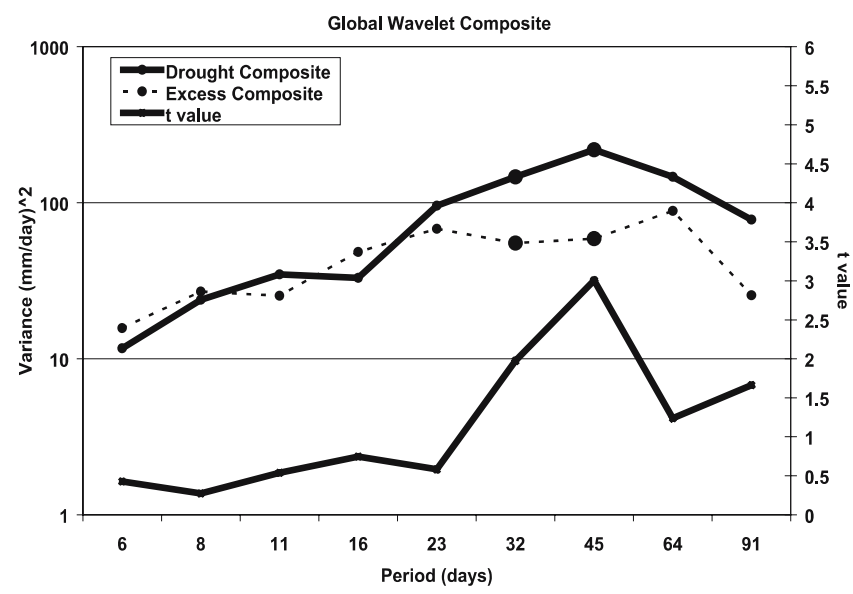

Figure 11. Composite global wavelet power spectrum for drought and good monsoon years. The calculated $t$ values for different periods are shown as continuous line. The critical $t$ value for $95 \%$ significance for degrees of freedom of 13 is 1.771 . The statistically significant differences between drought and good monsoon years are shown in larger symbol. The variance is in logarithmic scale.

to ENSO. Therefore, the interannual variation of the Indian monsoon cannot be considered as primarily arising from the interannual variation of intraseasonal variation.

\section{Active and break events and transitions: Time scales}

Two distinct approaches have been adopted in the study of intraseasonal variation. Here we have adopted, a more traditional approach, which focuses on special events, viz., active spells and breaks in the monsoon. These events are extremes of the intraseasonal fluctuation and it is important to predict them. The major features of these events have been elucidated for comparison with their simulation by models in order to understand the underlying mechanisms. In the second approach, the entire variation (and not just the extreme states) is viewed as a superposition of waves/modes or spatial patterns. Structure and evolution of these modes is investigated in detail for further understanding and generating predictions.

The analysis of active and break events has brought out the time scale of $3-4$ days as the dominant scale for the life-span of these events. The average life-span of breaks (6 days) is longer than that of active spells (4 days). The evolution of the composites (section 4) suggests a time scale of about 40 days. The other relevant time scale is the typical interval between the successive events. This time scale is best brought out by considering the variation of the monsoon zone rainfall with time. The dominant time scales of intraseasonal variation of monsoon circulation and convection are 10-20 days and 30-60 days with comparable contributions to the total intraseasonal variability in the Indian region (Goswami 2005 and references therein). Revival of the monsoon from breaks occurs either by westward propagation of synoptic scale systems generated over the Bay of Bengal across the core monsoon zone, or by northward propagation of the TCZ generated over the equatorial Indian Ocean onto the monsoon zone. While

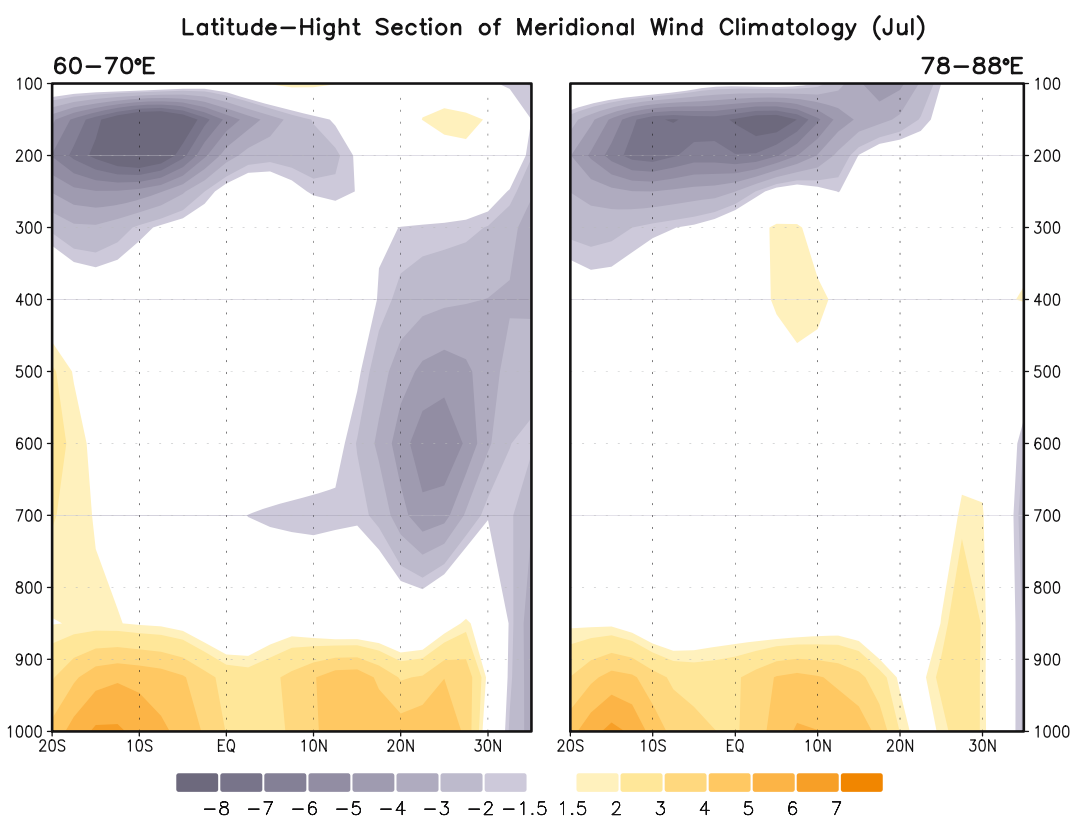

Figure 12. Latitude-height section of meridional wind climatology $\left(\mathrm{ms}^{-1}\right)$ during July. 

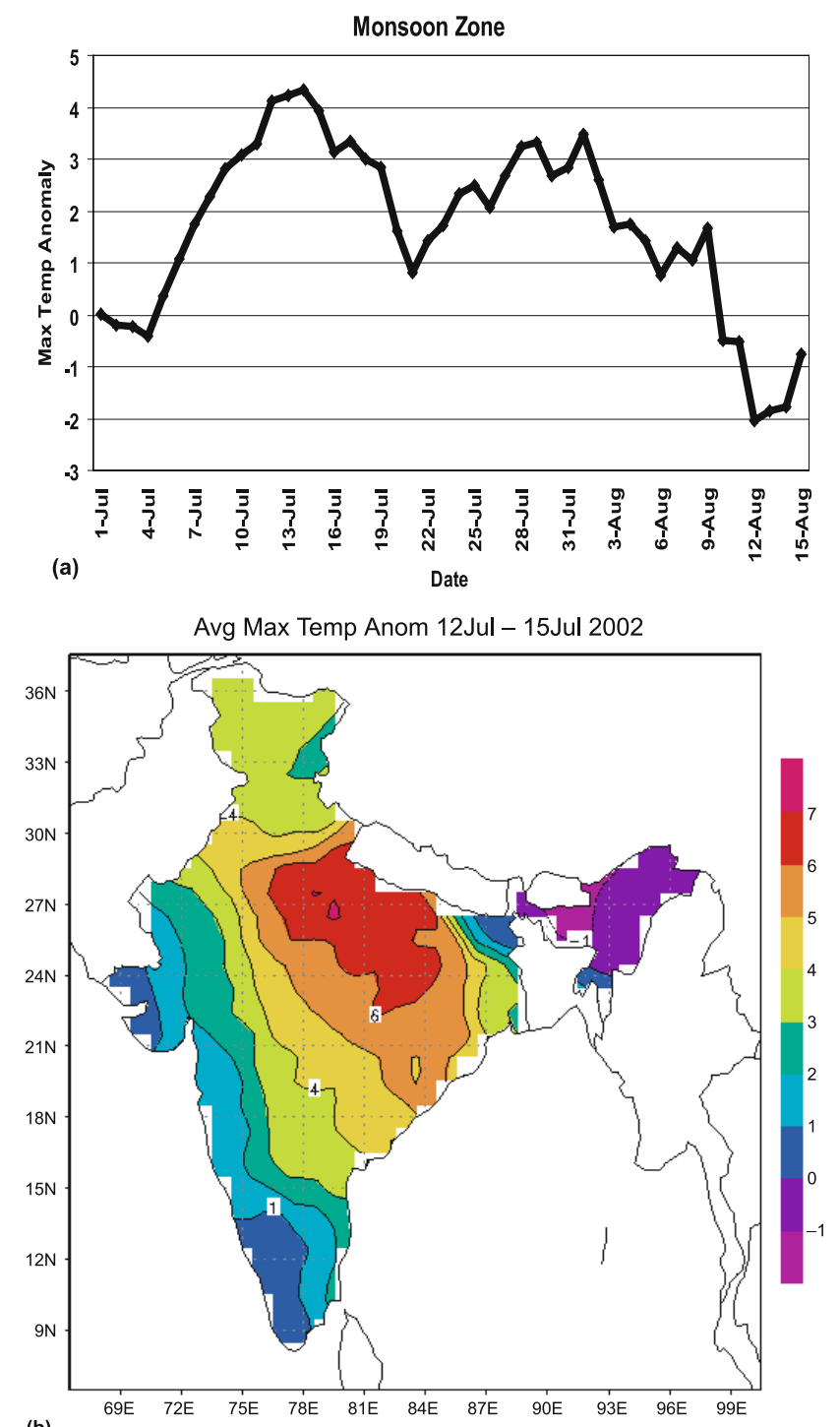

Figure 13. (a) Variation of day time (maximum) temperature anomaly $\left({ }^{\circ} \mathrm{C}\right)$ from 1 July to 15 August, 2002, averaged over monsoon core zone. (b) Average maximum temperature anomaly $\left({ }^{\circ} \mathrm{C}\right)$ averaged during the period $12-15$ July 2002 .

the quasi biweekly (10-20 days) scale is characterized by westward propagations (Krishnamurti and Bhalme 1976; Krishnamurti and Ardanuy 1980; Yasunari 1979), the 30-60-day scale is associated with northward propagations from the nearequatorial region (Annamalai and Sperber 2005). However, northward moving 30-60-day oscillations show considerable variation within the season as well as from one year to another.

Previous studies have shown significant differences in the strength of the ISOs, especially between a drought and good monsoon year. Lawrence and Webster (2001) examined the interannual variations of ISO activity using 22 years of OLR data. They found that summer time ISO activity exhibits strong inverse relationship with Indian monsoon. Over the 22 years of data examined, the relationship between Indian monsoon strength and ISO is comparable to or even stronger than the well documented relationship with El Niño/Southern Oscillation (ENSO). Here, we examine the variations of the strength of ISOs between drought and good monsoon years. For this purpose, we have carried out a wavelet analysis using daily rainfall data averaged over the monsoon core region from 1 May to 30 October. Wavelet analysis has been carried out for each of eight drought years $(1965,1966,1972,1979,1982$, 1987, 2002 and 2004) and seven good monsoon years $(1973,1975,1978,1988,1994,1998$ and 2003) separately and composite global wavelet power spectrum was calculated. The results are shown in figure 11. The statistical significance of the differences in the variance between the drought and good monsoon years has been calculated using two sample $t$-tests for unequal variances. The results are shown in figure 11 as $t$ values. The critical $t$ value for $95 \%$ significance for degrees of freedom of 13 is 1.771 . The differences in the variance between drought and good monsoon years, which are statistically significant at $95 \%$ level, are shown in larger size (symbol). The results suggest that there is no statistically significant difference in the shorter time scales. However, in the longer time scale (40-60 days), the differences between the drought and good monsoon years are statistically significant. This result suggests that oscillations of longer time scales dominate during the drought years. Kripalani et al (2004) also noted this kind of difference in the time periods of ISOs. The 30-60-day oscillation is linked to the Madden-Julian Oscillation (MJO), which is one of the dominant modes of tropical variability on intraseasonal time scales. It shows significant effect on the atmospheric circulation of the global tropics. Recently, Pai et al (2009) examined the impact of $\mathrm{MJO}$ on the active and break spells over the monsoon core region using the Wheeler-Hendon indices (Wheeler and Hendon 2004). The study revealed significant influence of MJO on the active and break phases of Indian monsoon. The peak phase of break spells are generally observed during the MJO phases of 1 and 2 (when the MJO phase is active over Africa/western parts of India). Subsequently as the MJO propagates eastwards, a gradual northward shift of the above normal rainfall band from south peninsula to north India is observed. It may be noted that MJO and the interannual background state modulates the activity in higher frequency modes. The total impact of the MJO extends into processes characterized by shorter time scales. For example, the MJO modulates the amplitudes and activities in equatorial waves and monsoon depressions. Thus, the activity in 


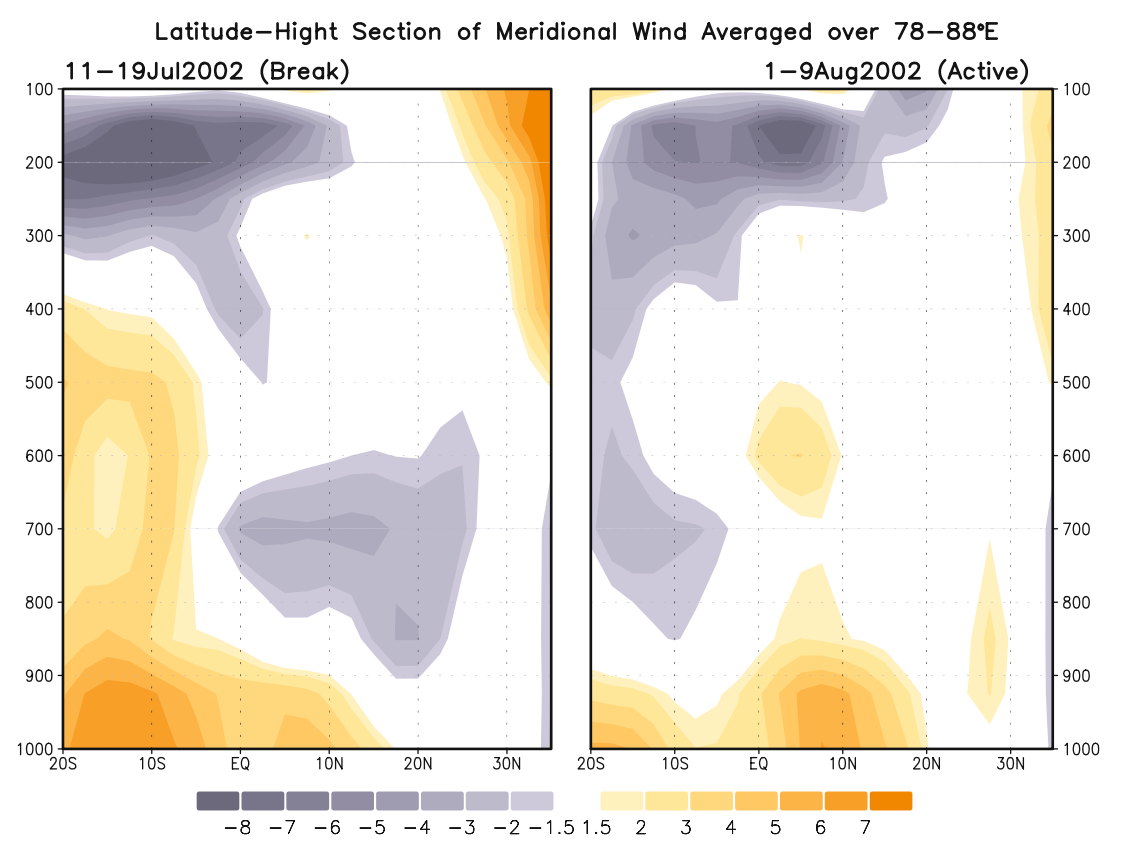

Figure 14. Latitude-height section of meridional wind $\left(\mathrm{ms}^{-1}\right)$ averaged over $78^{\circ}-88^{\circ} \mathrm{E}$ during (a) break period, $11-19$ July 2002 and (b) active period, 9-13 August 2002.

the 10-20-day band is not necessarily independent from the MJO.

\section{Long intense breaks and heat troughs}

Raghavan (1973) using synoptic data and few upper air data of IMD showed that during long intense breaks, the surface temperature increases rapidly and a heat-trough type circulation gets established over the monsoon trough zone. However, this important feature was not examined in detail in later studies. With the availability of quality controlled NCEP/NCAR reanalysis data, we revisit this observational aspect of the heattrough type circulation during intense breaks. The analysis of seasonal pattern of global divergent circulation by Trenberth et al (2000) showed that the first mode (i.e., complex empirical orthogonal function, CEOF1) explains about $60 \%$ of the variance, while the second mode (CEOF2) explains about $20 \%$ of the variance. The first mode has a simple vertical structure with a maximum in vertical motion around $400 \mathrm{hPa}$, convergence in the lower troposphere and divergence in the upper troposphere. Thus, the vertical structure of the first mode corresponds to that of the TCZ. The second mode is characterized by relatively shallow overturning with maximum vertical velocities near $800 \mathrm{hPa}$ and outflow from $750 \mathrm{hPa}$ to $350 \mathrm{hPa}$. This structure corresponds to a heat trough (Ramage 1971). Therefore, the heat trough-type circulation is revealed as the second mode of the seasonal global divergent circulation.

The surface low pressure belt over the Indian region during the summer monsoon comprises a well marked heat low over the northwestern region and a low pressure belt associated with the moist convective regime characterizing the $\mathrm{CTCZ}$, extending westward from the north Bay of Bengal (figure 12). We have constructed vertical profile of mean meridional circulation for July, over the western and eastern sectors of the CTCZ region. The observed vertical profile of the mean meridional circulation for July (figure 12) over the western $\left(65-70^{\circ} \mathrm{E}\right)$ and eastern $\left(78-88^{\circ} \mathrm{E}\right)$ sectors clearly brings out the shallow cell associated with the heat low over the western sector in contradistinction to the deep overturning associated with the CTCZ over the eastern sector.

During long intense breaks, the surface temperature increases rapidly and a heat-trough type circulation gets established over the monsoon trough zone (Raghavan 1973). Here, we consider a case study of a long intense break occurred during the 2002 monsoon season to see the variation of surface features and associated vertical circulation. The variation of the maximum temperature anomaly averaged over the monsoon zone, during June-August 2002 is shown in figure 13(a). It is seen that the surface temperature increased rapidly during the break of 4-17 July with the day time temperature anomaly exceeding $3{ }^{\circ} \mathrm{C}$, for many days. The spatial variation of the temperature anomaly for the peak break days (12-15 July) 
is shown in figure $13(\mathrm{~b})$, which shows the temperature anomalies $5^{\circ} \mathrm{C}$ over most parts of the CTCZ region. The meridional wind, averaged over the longitudes $78-88^{\circ} \mathrm{E}$, for the peak break days (11-19 July) is shown in figure 14(a). It is seen that a shallow meridional cell characteristic of a heat low prevails with convergence restricted to below $800 \mathrm{hPa}$ and northerlies prominent around $700 \mathrm{hPa}$. The occurrence of a heat trough type circulation in the peak monsoon months of July and August over the monsoon zone in place of a TCZ implies a major transition. Revival from such breaks involves a transition to a moist convective regime with convergence up to the mid-troposphere and northerlies aloft. This is illustrated in figure 14(b) which shows the vertical variation of the meridional wind, averaged over $78-88^{\circ} \mathrm{E}$, for the active spell after revival from the break with northerlies only above $300 \mathrm{hPa}$. More analyses of such intense break and active events are however, required to understand the physical mechanisms involved in the transition from heat trough circulation to moist circulation. This observed difference in the vertical circulation between the active and break events may be used as a metric to examine the fidelity of climate and numeric models in simulating the active and break spells of Indian monsoon.

\section{Summary and conclusions}

The identification of active and break events is based on the daily rainfall data averaged over the monsoon core zone which is coherent with respect to intraseasonal variation and over which large fluctuations of rainfall occur on this scale. The interannual variation of all-India summer monsoon rainfall (ISMR) is highly correlated with that of the summer monsoon rainfall over the core monsoon zone suggesting that it is a critical region for interannual variation as well as intraseasonal variation of the monsoon. The break (active) spell has been identified as the period during which the standardized rainfall anomaly is less (more) than -1.0 $(+1.0)$, consecutively for three days or more. The break periods identified in this study are comparable with those defined by Ramamurthy (1969), De et al (1998) and there is a very large overlap with those identified by Gadgil and Joseph (2003). During the drought years like 1965, 1966, 1968, 1972, 1979 and 1982, there is a maximum overlap of break days among the three methods discussed. These criteria can be operationally applied to monitor the active and break events of the Indian summer monsoon. Using the new criteria, India Meteorological Department (IMD) is monitoring the active and break events on an operational basis.
We find that breaks tend to have a longer lifespan (average 6 days) than active spells (average 4 days). While, almost $80 \%$ of the active spells lasted 3-4 days, only $40 \%$ of the break spells were of such short duration. A small fraction (9\%) of active spells and $32 \%$ of break spells lasted for a week or longer. While active events occurred almost every year, not a single break occurred in $26 \%$ of the years. On an average, there are 7 days of active and break events during the period July and August. Number of break days is significantly correlated with the ISMR. However, even in the absence of breaks, the rainfall was deficient by almost $10 \%$ in 1991 and with only three break days, the season of 1974 was a drought. The correlation with the number of active days is relatively poor. The time series analysis of active and break days shows no significant trends in either the days of active events or break events during the monsoon season. This is in contradiction to Joseph and Simon (2005)'s conclusion of an increasing trend in the number of break days. A possible reason for the difference could be their use of wind data (which forms the basis of their definition of breaks) from pre-satellite period up to the recent time for deriving the trend.

A wavelet analysis was made on the daily rainfall time series averaged over the core monsoon region to examine the differences in the ISOs between drought (8 years) and good monsoon (7 years) years. The composite global wavelet power spectrum shows that on longer time scale (30-60 days) there are statistically significant differences between the drought and good monsoon years. During the drought years, oscillations of longer time scales dominate.

The evolution of the lagged rainfall composites associated with the break and active spells suggests that the revival from breaks seems to occur primarily from northward propagations of the maximum rainfall zone. We have shown that there are important differences between the spatial patterns of the active/break spells and those characteristic of interannual variation, particularly those associated with the link to ENSO. The signature over the eastern equatorial Indian Ocean on intraseasonal time scales is similar to that on the interannual time scales. For the first time, the present study has elucidated the difference in the vertical meridional circulation between the active spells with moist convection and intense break events with a heat trough type circulation with the help of NCEP-NCAR reanalysis data. It is important to unravel the factors that determine the transitions in space and time from a heat low type circulation to a moist convective regime characterizing the Continental Tropical Convergence Zone (CTCZ) and vice versa for developing suitable prediction tools. 


\section{Acknowledgements}

We are thankful to $\operatorname{Dr} \mathrm{P}$ A Francis and Mr O P Sreejith and for their support in preparing some of the diagrams used in this paper. We are also thankful to Dr John Fasullo and two anonymous reviewers for their critical comments and suggestions.

\section{References}

Alexander G, Keshavamurty R N, De U S, Chellappa R, Das S K and Pillai P V 1978 Fluctuations of monsoon activity; Indian J. Meteor. Geophys. 29 76-87.

Annamalai H and Slingo J M 2001 Active/break cycles: Diagnosis of the intraseasonal variability of the Asian Summer Monsoon; Climate Dynamics 18 85-102.

Annamalai H and Sperber K R 2005 Regional heat sources and the active and break phases of boreal summer intraseasonal (30-50 day) variability; J. Atmos. Sci. 62 $2726-2748$.

Blanford H F 1886 Rainfall of India; Mem. Ind. Met. Dept. $2217-448$

De U S, Lele R R and Natu J C 1998 Breaks in southwest monsoon, India Meteorological Department, Report No. 1998/3.

De U S and Mukhopadhyay R K 2002 Breaks in monsoon and related precursors; Mausam 53 309-318.

Ferranti L, Slingo J M, Palmer T N and Hoskins B 1997 Relations between intraseaonal and interannual monsoon variability as diagnosed from AMIP integrations; Quart. J. Roy Met. Soc. 123 1323-1357.

Gadgil Sulochana and Joseph P V 2003 On breaks of the Indian monsoon, Proc. Indian Acad. Sci. (Earth Planet. Sci.) 112 529-558.

Gadgil Sulochana, Vinayachandran P N and Francis P A 2003 Droughts of the Indian summer monsoon: Role of clouds over the Indian Ocean; Curr. Sci. $\mathbf{8 5}$ $1713-1719$.

Gadgil Sulochana, Vinaychandran P N, Francis P A and Siddhartha Gadgil 2004 Extremes of Indian summer monsoon rainfall, ENSO, equatorial Indian Ocean Oscillation; Geophys. Res. Lett. 31 doi: 10.1029/2004GL019733.

Gadgil Sulochana, Rajeevan M and Francis P A 2007 Monsoon variability: Links to major oscillations over the equatorial Pacific and Indian oceans; Curr. Sci. 93 182-194.

Goswami B N and Ajayamohan R S 2001 Intraseasonal oscillations and interannual variability of the Indian summer monsoon; J. Climate 14 1180-1198.

Goswami B N 2005 Intraseasonal variability (ISV) of south Asian summer monsoon; In: Intraseasonal Variability of the Atmosphere - Ocean Climate System (eds) Lau K and Waliser D, Springer - Praxis, Chichester, UK.

Goswami B N, Sengupta D and Suresh Kumar G 1998 Intraseaonal oscillations and interannual variability of surface winds over the Indian monsoon region; Proc. Indian Acad. Sci. (Earth Planet. Sci.) 107 45-64.

Goswami B N, Ajayamohan R S, Xavier P K and Sengupta D 2003 Clustering of low pressure systems during the Indian summer monsoon by intra-seasonal oscillations; Geophys. Res. Lett. 30(8) doi: 10.1029/2002GL016734.

Hartmann D L and Michelsen M L 1989 Intra-seasonal periodicities in Indian rainfall; J. Atmos. Sci. 46 $2838-2862$.
Ihara C, Kushnir $\mathrm{Y}$, Cane $\mathrm{M}$ A and De la Peña V 2007 Indian Summer Monsoon Rainfall and its Link with ENSO and the Indian Ocean Climate Indices; Int. J. Climatol. 27(2) 179-187.

Joseph P V and Simon A 2005 Weakening trend of the southwest monsoon current through peninsular India from 1950 to the present; Curr. Sci. 89 687-694.

Kalnay E and Coauthors 1996 The NCEP/NCAR 40Year Reanalysis Project; Bull. Amer. Meteor. Soc. 77 437-471.

Kripalani R H, Kulkarni A, Sabade S S, Revadekar J, Patwardhan S K and Kulkarni J 2004 Intraseasonal Oscillations during monsoon 2002 and 2003; Curr. Sci. 87 325-351.

Krishnamurti T N and Bhalme H N 1976 Oscillations of a monsoon system. Part 1. Observational aspects; J. Atmos. Sci. 33 1937-1954.

Krishnamurti T N and Ardanuy P 1980 The 10 to 20-day westward propagating mode and breaks in the monsoon; Tellus 32 15-26.

Krishnamurthy V and Shukla J 2000 Intra-seasonal and inter-annual variability of rainfall over India; J. Climate 13 4366-4377.

Krishnamurthy V and Shukla J 2007 Intraseasonal and seasonally persisting patterns of Indian monsoon rainfall; J. Climate 20 3-20.

Krishnamurthy V and Shukla J 2008 Seasonal persistence and propagation of intraseasonal patterns over the Indian summer monsoon region; Climate Dynamics $\mathbf{3 0}$ 353-369.

Krishnan R, Zhang C and Sugi M 2000 Dynamics of breaks in the Indian summer monsoon; J. Atmos. Sci. 57(9) 1354-1372.

Lawrence D M and Webster P J 2001 Interannual variations of the intraseasonal oscillation in the south Asian summer monsoon region; J. Climate 14 2910-2922.

Magana V and Webster P J 1996 Atmospheric circulations during active and break periods of the Asian monsoon; Preprints of the Eighth Conference on the Global OceanAtmosphere-Land System (GOALS), Amer. Meteorol. Soc., Atlanta, GA.

Mandke S, Sahai A K, Shinde M A, Susmitha Joseph and Chattopadhyay R 2007 Simulated changes in active/break spells during the Indian summer monsoon due to enhanced $\mathrm{CO}_{2}$ concentrations: Assessment from selected coupled atmosphere-ocean global climate models; Int. J. Climatol. 27 837-859.

Mooley D A and Shukla J 1987 Tracks of low pressure systems that formed over India, adjoining countries, Bay of Bengal and Arabian Sea in summer monsoon season during the period 1888-1983, Centre for Ocean, Land and Atmosphere (COLA), USA.

Murakami M 1976 Analysis of summer monsoon fluctuations over India; J. Met. Soc. Japan 54 15-31.

Pai D S, Jyoti Bhate, Sreejith O P and Hatwar H R 2009 Impact of MJO on the intraseasonal variation of summer monsoon rainfall over India; Climate Dynamics doi: 10.1007/s00382-009-0634-4.

Rao Y P 1976 Southwest monsoon India Meteorological Department. Meteorological Monograph Synoptic Meteorology, No.1/1976, Delhi, 367 pp.

Raghavan K 1973 Break monsoon over India; Mon. Wea. Rev. $10133-43$.

Rajeevan M, Bhate J, Kale J D and Lal B 2006 High resolution daily gridded rainfall data for the Indian region: Analysis of break and active monsoon spells; Curr. Sci. 91(3) 296-306.

Ramamurthy K 1969 Monsoon of India: Some aspects of the 'break' in the Indian southwest monsoon during July and 
August; Forecasting Manual 1-57 No. IV 18.3, India Met. Dept., Pune, India.

Ramage C S 1971 Monsoon Meteorology; Int. Geophys. Ser. Vol. 15, Academic Press, San Diego, California, $296 \mathrm{pp}$.

Rodwell M J 1997 Breaks in the Asian monsoon: The influence of Southern Hemisphere weather systems; J. Atmos. Sci. 54 2597-2611.

Rasmusson E M and Carpenter T H 1983 The relationship between eastern equatorial Pacific sea surface temperature and rainfall over India and Sri Lanka; Mon. Wea. Rev. $111517-528$.

Shepard D 1968 A two dimensional interpolation function for irregularly spaced data; In: Proc. 1968 ACM Natl. Conf. 517-524.

Sikka D R and Sulochana Gadgil 1978 Large-scale rainfall over India during the summer monsoon and its relation of the lower and upper tropospheric vorticity; Indian J. Meteorol. Hydrol. Geophys. 29 219-231.

Sikka D R and Sulochana Gadgil 1980 On the maximum cloud zone and the ITCZ over India longitude during the southwest monsoon; Mon. Wea. Rev. 108 1840-1853.

Sikka D R 1980 Some aspects of the large-scale fluctuations of summer monsoon rainfall over India in relation to fluctuations in the planetary and regional scale circulation parameters; Proc. Indian Acad. Sci. (Earth Planet. Sci.) 89 179-195.

Trenberth K E, Stepaniak D P and Caron J M 2000 The global monsoon as seen through the divergent atmospheric circulation; J. Climate 13 3969-3993.

Waliser D 2006 Intraseasonal variability in Asian monsoons (ed.) Wang B, Springer-Praxis, Chichester, UK, pp 203-257.

Waliser D E, Lau K M and Stern W 2003 Potential predictability of the MJO; Bull. Am. Meteor. Soc. doi: 10:1175/BAMS-84-1-33.

Wang B, Webster P J and Teng H 2005 Antecedents and self-induction of active-break south Asian monsoon unraveled by satellites; Geophys. Res. Lett. 32 doi: 10.1029/2004. GL 020996.

Webster P J, Magaña V O, Palmer T N, Shukla J, Tomas R A, Yanai M and Yasunari T 1998 Monsoons: Processes, predictability, and the prospects for prediction; J. Geophys. Res. 103 14,451-14,510.

Wheeler M C and Hendon H H 2004 An all-season realtime multi-variate MJO index: Development of an index for monitoring and prediction; Mon. Wea. Rev. 132 1917-1932.

Yasunari T 1979 Cloudiness fluctuations associated with the northern hemisphere summer monsoon; J. Meteor. Soc. Japan $\mathbf{5 7}$ 227-242. 